Article

\title{
Combined Modality Therapy Based on Hybrid Gold Nanostars Coated with Temperature Sensitive Liposomes to Overcome Paclitaxel-Resistance in Hepatic Carcinoma
}

\author{
Hongyan Zhu ${ }^{1, \dagger}$, Weili Han ${ }^{1,+}$, Ye Gan ${ }^{1}$, Qiaofeng $\mathrm{Li}^{2,3}$, Xiaolan Li ${ }^{2,4}$, Lanlan Shao ${ }^{1}$, \\ Dan Zhu ${ }^{4, *}$ and Hongwei Guo ${ }^{2,4, *}$ \\ 1 College of Pharmacy, Nantong University, Nantong 226001, China; amy600@ntu.edu.cn (H.Z.); \\ pisces_lier@163.com (W.H.); 1823310018@stmail.ntu.edu.cn (Y.G.); 1923310020@stmail.ntu.edu.cn (L.S.) \\ 2 Key Laboratory of Longevity and Aging-related Diseases of Chinese Ministry of Education \& Center for \\ Translational Medicine, Guangxi Medical University, Nanning 530021, China; \\ liqiaofeng@stu.gxmu.edu.cn (Q.L.); lixiaolan@stu.gxmu.edu.cn (X.L.) \\ 3 School of Preclinical Medicine, Guangxi Medical University, Nanning 530021, China \\ 4 College of Pharmacy, Guangxi Medical University, Nanning 530021, China \\ * Correspondence: zdgxmu2006@163.com (D.Z.); hongweiguo@gxmu.edu.cn (H.G.); \\ Tel.: +86-0771-5358-014 (D.Z.); +86-0771-5605-911 (H.G.) \\ + These authors contributed equally to this work.
}

Received: 18 November 2019; Accepted: 13 December 2019; Published: 15 December 2019

\begin{abstract}
In this study, we prepared gold nanostar (GNS) composite nanoparticles containing siRNA of cyclooxygenase-2(siCOX-2) that were modified by tumor targeting ligand 2-deoxyglucose (DG) and transmembrane peptide 9-poly-D-arginine (9R) to form siCOX-2(9R/DG-GNS). Paclitaxel loaded temperature sensitive liposomes (PTX-TSL) were surface-modified to produce PTX-TSL-siCOX-2(9R/DG-GNS) displaying homogeneous star-shaped structures of suitable size $(293.93 \mathrm{~nm} \pm 3.21)$ and zeta potentials $(2.47 \mathrm{mV} \pm 0.22)$. PTX-TSL-siCOX-2(9R/DG-GNS) had a high thermal conversion efficiency under $808 \mathrm{~nm}$ laser radiation and a superior transfection efficiency, which may be related to the targeting effects of DG and increased heat induced membrane permeability. COX-2 expression in HepG2/PTX cells was significantly suppressed by PTX-TSL-siCOX-2(9R/DG-GNS) in high temperatures. The co-delivery system inhibited drug-resistant cell growth rates by $\geq 77 \%$ and increased the cell apoptosis rate about $47 \%$ at elevated temperatures. PTX-TSL and siCOX-2 loaded gold nanostar particles, therefore, show promise for overcoming tumor resistance.
\end{abstract}

Keywords: gold nanostars; temperature sensitive liposome; siCOX-2; paclitaxel-resistance; hepatic carcinoma

\section{Introduction}

Paclitaxel is widely administered to patients with breast and ovarian cancer and is beneficial to the treatment of lung and neck cancer [1,2]. Although paclitaxel is an effective chemotherapeutic agent, several mechanisms of paclitaxel resistance that impede its clinical efficacy have been reported [3-6], including the overexpression of P-glycoprotein (P-gp), resulting in increased drug efflux from tumour cells [7-9], microtubule mutations, and the overexpression of anti- and pro-apoptotic members of the B-cell lymphoma-2 (Bcl-2) family [10-12]. Due to drug resistance, epothilones (paclitaxel analogues) have replaced paclitaxel for cancer therapy, but their clinical efficacy is limited. In addition, new cytotoxic drugs have been developed for paclitaxel resistant ovarian cancer, but remission rates remain 
as high as $15 \%-25 \%$ [13]. The use of agents that inhibit P-gp mediated drug efflux are another attractive strategy, but they are still under clinical trial, with their therapeutic benefits remaining unknown [14]. Therefore, new therapeutic strategies to improve paclitaxel resistance are urgently required.

Temperature-sensitive liposome (TSL) can improve antitumor drug efficacy and reduce drug side effects [15-20]. The treatment process is initiated by heating, which can be advantageous. At high temperatures, TSL increases the release of encapsulated anticancer drugs at the tumor site [21,22]. Additionally, hyperthermia (HT) $\left(41-43^{\circ} \mathrm{C}\right)$ can inhibit tumor cell processes, enhance blood flow [23], and increase the permeability of tumor vessels to drug delivery systems [24]. The combination of HT and TSL can improve drug delivery and efficacy [25].

Gold nanoparticles can be combined with many drugs, permitting diverse biomedical applications, including delivery systems, medical imaging, and diagnostics [26]. Gold nanostars (GNS) are a new type of gold nanoparticle with excellent physical and chemical properties. They are capable of converting light into heat when light irradiation's wavelength coincides with the unable surface plasmon resonance (SPR) of GNS [27,28]. In addition, GNS modifications exhibit plasmons in the near-infrared (NIR) region, making GNS a photothermal treatment option that can specifically target tumor cells when their surface is further modified with target ligands. Moreover, the cutting-edge structure of GNS displays increased heat production capacity and deep penetration into the tumor tissue, minimizing tumor drug resistance [29-35].

Cyclooxygenase-2 (COX-2) is a key metabolite of arachidonic acid and plays a major role in tumorigenesis, apoptosis, and angiogenesis [36-38]. Numerous studies have reported that high COX-2 expression is an early marker of tumor development [39-45]. In addition, COX-2 is involved in inducing multi-drug resistance in tumors through increased Bcl2 expression [46] and upregulating multi-drug resistance related proteins $[47,48]$. Hence, COX-2 silencing using small interfering RNAs (siRNAs) can suppresses drug resistance in tumor cells.

Here, we prepared siCOX-2-loaded composite GNS modified with 2-deoxyglucose (DG) and 9 polyarginine (9R) to form siCOX-2(9R/DG-GNS). A co-delivery system of paclitaxel-loaded temperature sensitive liposomes (PTX-TSLs) and siCOX-2(9R/DG-GNS) was further constructed to form PTX-TSL-siCOX-2(9R/DG-GNS) (Figure 1). The photothermal effects of GNS permitted phase transition temperatures of the liposomes. After heating, the PTX was simultaneously released and siCOX-2(9R/DG-GNS) was exposed. siCOX-2(9R/DG-GNS) was then taken up by drug-resistant tumor cells through the active targeting role of DG. The co-delivery of PTX-TSL-siCOX-2(9R/DG-GNS) was thus predicted to overcome paclitaxel resistance in cancer cells.

\section{Materials and Methods}

\subsection{Materials}

Polyethylene glycol (PEG, relative molecular mass: 2000, 98.6\%), 1, 2-distearoyl-sn-glycero-3phosphoethanolamine-PEG-SH (DSPE-PEG-SH, relative molecular mass: 5000, 97.0\%) and 9 polyarginine (9R, 98.0\%) were synthesized by GL Biochem Ltd. (Shanghai, China). 2-amino-2deoxy-D-glucose hydrochloride (DG. $\mathrm{HCl}, 97.0 \%$ ), n-hydroxy-succinamide (NHS, 99.0\%), dicyclohexyl carbodiimide (DCC, 99.0\%), 1-(3-Dimethylaminopropyl)-3-ethylcarbodiimide hydrochloride (EDC, 99.0\%) and L-cysteine (Cys) were purchased from Aladdin Reagents (Shanghai, China). 3-(4, 5-dimethylthiazol-2-yl)-2, 5-diphenyltetrazolium bromide (MTT), RPMI 1640, DMEM high-glucose medium, fetal bovine serum (FBS), penicillin, streptomycin and trypsin were purchased from Gibco (New York, NY, USA). Paclitaxel (PTX, 99.0\%) was purchased from Jiangsu yew pharmaceuticals (Wuxi, China). 1, 2-dipalmitoyl-sn-glycero-3-phosphocholine (DPPC, 99.0\%), 1-stearoyl-2-hydroxy-sn-glycero-3-phosphocholine (MSPC, 99.0\%) and cholesterol were purchased from Avanti (Alabaster, AL, USA). COX-2 siRNA (sense strand, 5'-AAC UGC UCA ACA CCG GAA Utt-3', antisense strand $5^{\prime}$-AUU CCG GUG UUG AGC AGU Utt-3') and the non-specific control siRNA (NC siRNA) (sense strand, 5' -UUC UCC GAA CGU GUC ACG U-3' , antisense strand 5'-ACG 
UGA CAC GUU CGG AGA A-3') were purchased from Biomics Biotechnologies (Shanghai, China). The primary antibodies including anti-COX-2 from Cell Signaling Technology (Danvers, MA, USA) and anti-GAPDH from KANCHEN (Shanghai, China). The secondary antibodies included IRDye 680-labeled secondary antibodies from Santa Cruz Biotech (Santa Cruz, CA, USA). Other experimental reagents were purchased from the Shanghai Chemical Reagent Company (Shanghai, China).

\subsection{Synthesis of the DG-PEG-Cys-9R Complex}

\subsubsection{DG-PEG Synthesis}

The first step was to protect the amino group of $\mathrm{NH}_{2}$-PEG-COOH by di-tert-butyl pyrocarbonate $\left((\mathrm{Boc})_{2} \mathrm{O}\right) \cdot \mathrm{NH}_{2}-\mathrm{PEG}-\mathrm{COOH}$ was dissolved in Dichloromethane and the catalyst 4-dimethylaminopyridine (DMAP) was added. After stirring for $5 \mathrm{~min},(\mathrm{Boc})_{2} \mathrm{O}$ was added dropwise under ice bath conditions and stirred for $30 \mathrm{~min}$. The solution was purified by dialysis (MW 2000) after stirring overnight at room temperature. The ninhydrin reaction was used to verify the successful protection by $(\mathrm{Boc})_{2} \mathrm{O}$.

Step two was the carboxyl group of $\mathrm{NH}_{2}$-PEG-COOH with Boc-protected amine reacting with DG. Firstly, the carboxyl group of $\mathrm{NH}_{2}$-PEG-COOH was catalytically activated by a DCC/NHS system (molar ratio of PEG:DCC:NHS = 1:1.8:2.25) in anhydrous dimethylformamide (DMF) solution with continuous stirring overnight at room temperature. Centrifugation was performed to remove byproducts before DG. $\mathrm{HCl}$ was dissolved in the activated PEG solution with stable stirring for $4 \mathrm{~h}$ (molar ratio of PEG:DG =1:0.8). The obtained DG-PEG complex was then dissolved in a mixed solution of dichloromethane and trifluoroacetic acid with constant agitation (volume ratio: 7:3) to remove the Boc-protection on amino group of $\mathrm{NH}_{2}$-PEG-COOH. The DG-PEG complex was then purified by dialysis (MW 2000) and obtained by lyophilization.

\subsubsection{Synthesis of DG-PEG-Cys Complex}

The amine group of L-Cysteine (Cys) was protected by $(\mathrm{Boc})_{2} \mathrm{O}$, in a similar fashion to the amino group of $\mathrm{NH}_{2}-\mathrm{PEG}-\mathrm{COOH}$ by $(\mathrm{Boc})_{2} \mathrm{O}$. The carboxyl group of $\mathrm{Cys}$ was activated by a DCC/NHS catalyst system (molar ratio of PEG:DCC:NHS = 1:1.8:2.25). The prepared DG-PEG complex was reacted with the activated solution with stable stirring for $4 \mathrm{~h}$. The products were dissolved in a mixed solution of dichloromethane and trifluoroacetic acid (volume ratio of 7:3). Finally, DG-PEG-Cys was purified by dialysis (MW 2000) and obtained via rotary evaporation. $\mathrm{NH}_{2}-\mathrm{PEG}-\mathrm{OCH}_{3}$ without DG modifications was used for the reaction with the Cys to obtain the Cys-PEG-OCH $\mathrm{H}_{3}$ as a control.

\subsubsection{Synthesis of the DG-PEG-Cys-9R Complex}

EDC and NHS (molar ratio of 9R:EDC:NHS = 1:1.2:1.5) was used to activate the carboxy group of $9 \mathrm{R}$ (the terminal amine group protected by 9-fluorenylmethyloxycarbony (Fmoc)) for $4 \mathrm{~h}$ at room temperature. Then, the activated carboxy group of $9 \mathrm{R}$ was allowed to bond with the amine group of DG-PEG-Cys with constant stirring for $4 \mathrm{~h}$ at room temperature. The synthetic products were dissolved in a mixed solution of dimethyformamide (DMF) solution and $20 \%$ piperidine (volume ratio of 7:3) to divest Fmoc. Finally, the DG-PEG-Cys-9R complex was obtained (molar ratio of 9R:DG-PEG-Cys = 1:1.5). The experimental control group $\mathrm{H}_{3} \mathrm{CO}-\mathrm{PEG}-\mathrm{Cys}-9 \mathrm{R}$ was the same as above.

\subsection{Preparation of siCOX-2(9R/DG-GNS)}

\subsubsection{Preparation of GNS}

GNS was prepared via the seed growth method. Chloroauric acid $\left(\mathrm{HAuCl}_{4}\right)$ solution $(10 \mathrm{mmol} / \mathrm{L})$, $9.75 \mathrm{~mL} \mathrm{H}_{2} \mathrm{O}, 1 \mathrm{~mol} / \mathrm{L}$ hydrochloric acid and $100 \mu \mathrm{L}$ seed solution were successively added to a $10 \mathrm{~mL}$ reaction bottle in a $25^{\circ} \mathrm{C}$ water bath. Silver nitrate $\left(\mathrm{AgNO}_{3}\right)(2 \mathrm{~mol} / \mathrm{L}, 100 \mu \mathrm{L})$ and ascorbic acid (AA) $(100 \mathrm{mmol}, 50 \mu \mathrm{L})$ were also added. GNS solution was obtained after stirring for $30 \mathrm{~s}$. 


\subsubsection{Preparation of $9 R / D G-G N S$}

DG-PEG-Cys-9R (0.05 mmol) was fully dissolved in $\mathrm{H}_{2} \mathrm{O}$ and $0.04 \mathrm{mmol}$ GNS $(10 \mathrm{~mL})$ was added with stirring for $12 \mathrm{~h}$ at room temperature. 9R/DG-GNS was obtained and modified by $9 \mathrm{R}$ and DG simultaneously. Similarly, GNS reacted with $\mathrm{H}_{3}$ CO-PEG-Cys-9R to obtain 9R-GNS as a control.

\subsubsection{Preparation of siCOX-2(9R/DG-GNS)}

9R/DG-GNS and siCOX-2 (molar ratio of 1:1) were mixed and incubated on ice for $45 \mathrm{~min}$ to obtain siCOX-2-loaded 9R/DG-GNS(siCOX-2(9R/DG-GNS)). siCOX-2(9R-GNS) was obtained as control using the same method.

\subsection{Preparation of PTX-TSL-siCOX-2(9R/DG-GNS)}

DPPC (90 mg), MSPC (5 mg), DSPE-PEG-SH (10 mg), cholesterol (10 mg) at molar ratios of 9:0.5:1:1 and PTX (9 mg) (molar ratio of paclitaxel:phospholipid $=1: 10$ ) were dissolved in $5 \mathrm{~mL}$ of chloroform which was volatilized by vacuum evaporation forming a thin film on the bottle wall. The remaining chloroform was removed by rotary evaporation. Phosphate buffer saline (PBS) $(21 \mathrm{~mL})$ was added to hydrate for $2 \mathrm{~h}$ at $60^{\circ} \mathrm{C}$ and siCOX-2(9R/DG-GNS) was added to the aqueous solution for further hydration overnight. Mixtures were sonicated for $10 \mathrm{~min}$ and filtered $(0.22 \mu \mathrm{m}$ membrane). The co-delivery PTX-loaded and siCOX-2(9R/DG-GNS) (PTX-TSL-siCOX-2(9R/DG-GNS)) system were obtained. PTX-TSL without siCOX-2(9R/DG-GNS) was obtained as control.

\subsection{Characterization of PTX-TSL-siCOX-2(9R/DG-GNS)}

\subsubsection{Characterization of DG-PEG-Cys-9R Complex}

The synthesis of DG, HOOC-PEG-NH ${ }_{2}$, DG-PEG-Cys, $\mathrm{H}_{3}$ CO-PEG-NH ${ }_{2}$ and $\mathrm{H}_{3}$ CO-PEG-Cys was identified by ${ }^{1} \mathrm{H}$ nuclear magnetic resonance $\left({ }^{1} \mathrm{H}\right.$ NMR) spectra. Using deuterium dimethyl sulfoxide (DMSO) as the solvent DG, HOOC-PEG-NH $\mathrm{N}_{2}$, DG-PEG-Cys, $\mathrm{H}_{3} \mathrm{CO}-\mathrm{PEG}-\mathrm{NH}_{2}$ and $\mathrm{H}_{3} \mathrm{CO}-\mathrm{PEG}-\mathrm{Cys}$ with a mass concentration of $2 \mathrm{mg} / \mathrm{mL}$ was prepared for the assessment of its nuclear magnetic spectrum.

SDS-PAGE was performed on acrylamide gels (7.5\% resolving gel, $4 \%$ stacking gel) to identify the DG-PEG-Cys-9R and $\mathrm{H}_{3} \mathrm{CO}-\mathrm{PEG}-\mathrm{Cys}-9 \mathrm{R}$ systems.

\subsubsection{Physicochemical Property of Hybrid Gold Nanostars}

The Fourier transform infrared (FTIR) spectra of GNS, 9R/DG-GNS, TSL and TSL-(9R/DG-GNS) were recorded using a FTIR spectrometer (Thermo Fisher Scientific, Waltham, MA, USA). We also recorded the FTIR spectra of DG, HOOC-PEG-NH ${ }_{2}$, DG-PEG and DG-PEG-Cys as control groups.

The hydrodynamic diameter, PDI, and zeta potential of hybrid GNS were measured using a Malvern Zetasizer Nano ZS90 (Malvern Instrument Ltd., Worcestershire, UK). The morphologies of the nanoparticles were imaged via JEM-1011transmission electron microscope (TEM) (JEOL, Tokyo, Japan). UV-VIS-NIR spectra were obtained on a 754 PC spectrometer (Jinghua Instruments, Shanghai, China).

The photothermal potential of prepared PTX-TSL-siCOX-2(9R/DG-GNS) was investigated by NIR laser irradiation $(808 \mathrm{~nm})$ (LEO-Photoelectric, Shenzhen, China). The temperature was monitored with a thermometer every $30 \mathrm{~s}$ for $10 \mathrm{~min}$. The photothermal performances of PTX-TSL-siCOX-2(9R/DG-GNS) under various laser intensities and different concentrations of samples were investigated respectively. In addition, GNS and GNS composite carriers were irradiated for $10 \mathrm{~min}$ and photothermal performances were monitored. We also investigated the photothermal performances of 9R, DG, HOOC-PEG-NH $\mathrm{N}_{2}$, 9R/DG and 9R/DG-GNS alone, which served as negative controls. To further demonstrate the photothermal stability of PTX-TSL-siCOX-2(9R/DG-GNS), the photothermal efficiency was tested for five cycles of NIR laser irradiation and cooling down. 
To assess the binding ability of hybrid gold nanostars with siCOX-2, different siCOX-2 ratios were assessed (molar ratio of 1:0, 1:1, 1:5, 1:10, 1:20, 1:40, 1:60) at $4{ }^{\circ} \mathrm{C}$ for $45 \mathrm{~min}$. Prepared samples were run on $4 \%$ agarose gels at $120 \mathrm{~V}$ for $20 \mathrm{~min}$ and imaged.

To examine the drug-loading properties of temperature sensitive liposomes in detail, high-performance liquid chromatography (HPLC) (Shimadzu, Kyoto, Japan) was used to detect the PTX content of PTX-TSL-siCOX-2(9R/DG-GNS). The chromatographic conditions were as follows: detection wavelength: $227 \mathrm{~nm}$; column: C18; mobile phase: water-acetonitrile-methanol (38:40:22); injection volume: $20 \mu \mathrm{L}$; flow rate: $1 \mathrm{~mL} / \mathrm{min}$, column temperature: $25^{\circ} \mathrm{C}$. A PTX standard curve was constructed by dissolving the temperature-sensitive liposome solution containing PTX and filtering through $0.45 \mu \mathrm{m}$ membranes. Drug loading and encapsulation efficiency were calculated under the above liquid phase conditions and estimated from the following formula:

$$
\begin{gathered}
\text { Drug loading efficiency } \%=\frac{\text { weight of drug in liposomes }}{\text { weight of liposomes }} \times 100 \% \\
\text { Encapsulation efficiency } \%=\frac{\text { weight of drug in liposomes }}{\text { weight of drug added }} \times 100 \% \text {. }
\end{gathered}
$$

The phase change temperature of the temperature sensitive liposome were measured by a differential scanning calorimeter (DSC) (Netzsch, Selb, Bavaria, Germany).

The dialysis method was used to detect the release properties of temperature-sensitive liposomes under different temperature conditions. PTX-TSL and PTX-TSL-siCOX-2(9R/DG-GNS) were added to dialysis bags and $250 \mathrm{~mL}$ of $30 \%$ ethanol in PBS was used as the dialysis medium. The dialysis media ( $1 \mathrm{~mL}$ ) was collected at $0,1,5,10,20,40,60 \mathrm{~min}$ and added to an equal volume of PBS. The amount of PTX released in the dialysis medium was determined by HPLC. The release percentage of PTX was calculated as the formula of weight (cumulative release of PTX)/weight (total PTX).

To investigate the stability of the co-delivery system, the particle sizes and PDI of PTX-TSL-siCOX-2(9R/DG-GNS) were detected at different weeks: 1,2 , and 3 at $4{ }^{\circ} \mathrm{C}$.

\subsection{Cell Experiments}

\subsubsection{Cell Biocompatibility}

MTT assay was performed to assess the cytotoxicity of free GNS and GNS composite carriers. Briefly, Human Umbilical Vein Endothelial Cells (HUVECs) were cultured in RPMI 1640 medium containing $10 \%$ (v/v) FBS, streptomycin $(100 \mu \mathrm{g} / \mathrm{mL})$ and penicillin $(100 \mathrm{U} / \mathrm{mL})$ at $37^{\circ} \mathrm{C}$ in $5 \% \mathrm{CO}_{2}$. Cells were seeded at 5000 cells/well in 96-well plates (Corning Inc., New York, NY, USA) and allowed to grow into $70 \%-80 \%$ confluency. Then, cells were treated with GNS and GNS composite carriers in RPMI 1640 medium $(200 \mu \mathrm{L})$ at concentrations ranging from 0.01 to $1000 \mu \mathrm{mol} / \mathrm{L}$ for $48 \mathrm{~h}$. Cells were incubated in MTT reagent for $4 \mathrm{~h}$ and $150 \mu \mathrm{L}$ DMSO was added to dissolve the intracellular formazan crystals. Optical densitie (OD) at $490 \mathrm{~nm}$ was detected using an Infinite F200 (TecanInc, Zurich, Switzerland). Cell viability (\%) was calculated as the $\mathrm{OD}_{\text {treated }} / \mathrm{OD}_{\text {control }} \times 100 \%$, where $\mathrm{OD}_{\text {treated }}$ represents the $\mathrm{OD}$ in the presence of GNS and GNS composite carrier while $\mathrm{OD}_{\text {control }}$ is the absorbance of cells not treated with GNS and the GNS composite carrier.

\subsubsection{In Vitro Cellular Uptake Assays}

PTX-resistant HepG2/PTX cells were seeded in a $35 \mathrm{~mm}^{2}$ petri dishes (MatTek, Ashland, MA, USA) at a density of $1.0 \times 10^{5}$ cells/well and grown for $24 \mathrm{~h}$ at $37{ }^{\circ} \mathrm{C}$ in $5 \% \mathrm{CO}_{2}$. The nucleus was stained by 4, 6-Diamidino-2-Phenylindole (DAPI) overnight according to the manufacturer's protocol. Cells were transfected with Carboxyfluorescein (FAM) labeled siRNA delivery systems (siCOX-2(GNS), siCOX-2(9R-GNS), siCOX-2(9R/DG-GNS), PTX-TSL-siCOX-2(9R/DG-GNS)). The final concentration of FAM-siRNA was $50 \mathrm{nM}$. After incubation for $4 \mathrm{~h}$, the medium was discarded and the cells were 
rinsed 3 times with PBS (PH = 7.4). The uptake of siRNA and GNS complexes was assessed through imaging on a Leica TCS SP5 confocal laser-scanning microscope (CLSM) (Leica, Buffalo Grove, IL, USA). FAM-labeled siRNA had an excitation wavelength of $492 \mathrm{~nm}$. All images were quantified using ImageJ software (National Institutes of Health; Bethesda, MD, USA).

\subsubsection{Analysis of In Vitro Gene Silencing}

COX-2 expression in PTX- resistant HepG2 cells was assessed by a Western blot analysis following treatment with different concentrations of free siCOX-2, GNS complexes (siCOX-2/9R-GNS, siCOX-2(9R/DG-GNS) and siCOX-2(9R/DG-GNS) $\left(43^{\circ} \mathrm{C}\right)(15 \mathrm{~min})$ ) and GNS-PTX complexes (PTX-TSL-siCOX-2(9R/DG-GNS), PTX-TSL-siNC(9R/DG-GNS) $\left(43{ }^{\circ} \mathrm{C}\right)(15 \mathrm{~min})$ and PTX-TSL-siCOX-2(9R/DG-GNS) $\left(43^{\circ} \mathrm{C}\right)$ ). Briefly, cells were lysed in lysis buffer containing $(50 \mathrm{mmol} / \mathrm{L}$ Tris- $\mathrm{HCl}, 100 \mathrm{mmol} / \mathrm{L} \mathrm{NaCl}, 1 \mathrm{mmol} / \mathrm{L} \mathrm{EDTA}, 3 \mathrm{mmol} / \mathrm{L} \mathrm{Na}_{3} \mathrm{VO}_{4}, 20 \mathrm{mmol} / \mathrm{L} \mathrm{NaF}, 1 \mathrm{mmol} / \mathrm{L} \mathrm{PMSF}$, supplemented with $1 \%$ Nonidet P-40 and protease inhibitor cocktail). BCA protein quantification assay was performed. Then, the samples with known concentrations were all dispersed in a loading buffer and heated at $95^{\circ} \mathrm{C}$ for $5 \mathrm{~min}$. The proteins of different samples (30 $\left.\mu \mathrm{g}\right)$ were separated on SDS-PAGE (10\%) gels for electrophoresis and transferred to nitrocellulose membranes. The membranes were blocked in 5\% non-fat milk powder for $2 \mathrm{~h}$ with slight shaking at room temperature. Then, the membranes were washed with TBST buffer $\left(996 \mathrm{~mL} \mathrm{H}_{2} \mathrm{O}, 6.057 \mathrm{~g}\right.$ Tris, $8.5 \mathrm{~g} \mathrm{NaCl}, 0.05 \%$ Tween 20, pH 7.5-7.6). Membranes were incubated overnight at $4{ }^{\circ} \mathrm{C}$ with anti-COX-2 (1:1000) and anti-GAPDH (1:1000) antibodies and washed three times in TBST for $30 \mathrm{~min}$. The GAPDH membrane and COX-2 membrane were then incubated with IRDye 680-labeled mouse and rabbit secondary antibodies $(1: 15,000)$ at room temperature for $2 \mathrm{~h}$ in the dark, respectively. The expression of DAPDH and COX-2 were assessed on an Odyssey CLx Western blot detection system (LI-COR Biosciences, Lincoln, NE, USA).

\subsubsection{Cell Growth and Anti-Tumor Drug Resistance}

MTT assays were used to evaluate the cytotoxicity of different composite carriers [49,50]. Briefly, PTX-resistant HepG2 cells (5000 cells per well) were plated into 96-well flat-bottomed microtiter plates to $70 \%-80 \%$ confluence prior to use. Then, the cells were treated with DMEM containing siNC(9R/DG-GNS), siCOX-2(GNS), siCOX-2(9R-GNS), siCOX-2(9R/DG-GNS), PTX-TSL-siNC(9R/DG-GNS) and PTX-TSL-siCOX-2(9R/DG-GNS) (final PTX concentration was $7 \mathrm{nM}$ ) for $48 \mathrm{~h}$. The final concentrations of siRNA (siNC and siCOX-2) were $25 \mathrm{nM}, 50 \mathrm{nM}$ and $100 \mathrm{nM}$. After $48 \mathrm{~h}$ incubation, the medium was removed and cells were incubated in MTT reagent $(20 \mu \mathrm{L}, 5 \mathrm{mg} / \mathrm{mL})$ for $4 \mathrm{~h}$. Then, $150 \mu \mathrm{L}$ DMSO was added to dissolve the MTT formazan crystal for $10 \mathrm{~min}$ and the ODs were detected at $490 \mathrm{~nm}$ according to manufacturer's protocol. Cell viability (\%) was defined as the $\mathrm{OD}_{\text {treated }} / \mathrm{OD}_{\text {control }} \times 100 \%$, where OD treated was the OD obtained in the presence of GNS and GNS composite carriers and the $\mathrm{OD}_{\text {control }}$ was the absorbance of untreated cells.

\subsubsection{Cell Apoptosis Assay}

PTX-resistant HepG2 cells were seeded in a 24-well plate at a density of $5 \times 10^{4}$ cells per well. After $24 \mathrm{~h}$ of incubation, the medium was replaced with the medium containing siNC(9R/DG-GNS), siCOX-2(GNS), siCOX-2(9R-GNS), siCOX-2(9R/DG-GNS), PTX-TSLsiNC(9R/DG-GNS), PTX-TSL-siCOX-2(9R/DG-GNS) respectively (the concentration of siRNA was $50 \mathrm{nM}$; the concentration of PTX was $7 \mathrm{nM}$. The heating groups were incubated at $43{ }^{\circ} \mathrm{C}$ in $5 \% \mathrm{CO}_{2}$ for $15 \mathrm{~min}$ ). After being treated for $4 \mathrm{~h}$, the cells were collected by centrifugation and washed once with PBS. After cell suspension in $200 \mu \mathrm{L}$ binding buffer, staining was performed with propidium iodide (PI) and annexin V-FITC for $20 \mathrm{~min}$ at room temperature. The fluorescence intensities of cells were recorded by flow cytometry. 


\subsection{Statistical Analysis}

A statistical analysis was performed using GraphPad Prism software (Version 5.01) (GraphPad Software, San Diego, CA, USA). A student's $t$-test was used to analyze the differences between two independent groups. A $P$ value at 0.05 or less was considered statistically significant.

\section{Results and Discussion}

\subsection{Characterization of DG-PEG-Cys-9R, 9R/DG-GNS and TSL-9R/DG-GNS}

The chemical structure of PTX-TSL-siCOX-2(9R/DG-GNS) and the preparation process are illustrated in Scheme 1. The ${ }^{1} \mathrm{H}$ NMR spectra of DG-PEG-Cys demonstrated that 3.67-3.69 ppm and $4.02 \mathrm{ppm}$ belonged to DG; $3.51 \mathrm{ppm}$ and $3.34 \mathrm{ppm}$ belonged to $\mathrm{CH}_{2}$ of PE; 1.49-1.74 ppm and 5.57-5.59 ppm belonged to Cys and $2.50 \mathrm{ppm}$ corresponded to DMSO peak. The ${ }^{1} \mathrm{H}$ NMR spectra from H3CO-PEG-Cys demonstrated that $3.34 \mathrm{ppm}$ and $3.50 \mathrm{ppm}$ belonged to $\mathrm{CH}_{2}$ of $\mathrm{PEG}$ compared; $1.23-1.70 \mathrm{ppm}$ and 5.56-5.58 ppm belonged to Cys and $2.50 \mathrm{ppm}$ corresponded to DMSO peak. These data confirm the successful linkage of DG-PEG-Cys and H3CO-PEG-Cys.

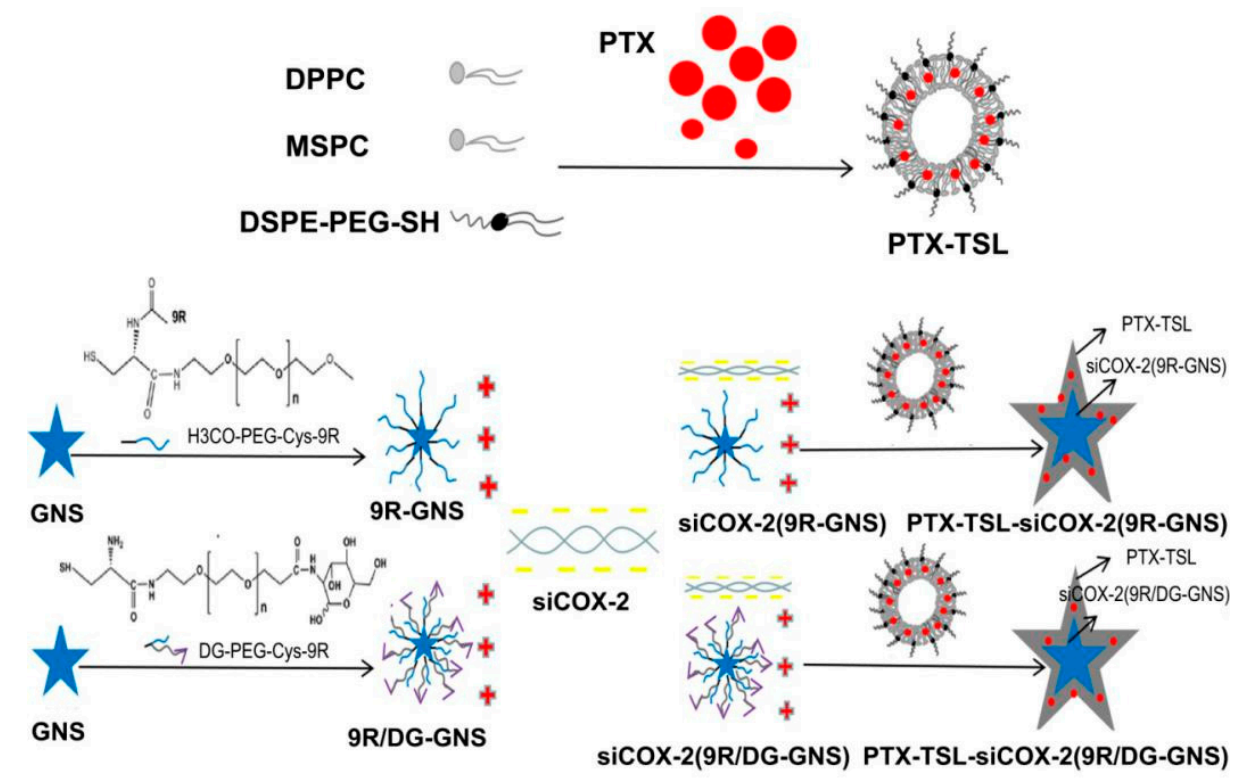

Scheme 1. Overview of the preparation of PTX-TSL-siCOX-2(9R/DG-GNS). DPPC: 1,2-dipalmitoylsn-glycero-3-phosphocholine; MSPC: 1-stearoyl-2-hydroxy-sn-glycero-3-phosphocholine; DSPE: 1,2-distearoyl-sn-glycero-3-phosphoethanolamine; PTX: Paclitaxel; TSL: temperature sensitive liposomes GNS: gold nanostars; DG: 2-deoxyglucose; 9R: 9-poly-D-arginine; PEG: polyethylene glycol; Cys: cysteine.

The successful conjugation of DG-PEG-Cys and 9R, $\mathrm{H}_{3} \mathrm{CO}-\mathrm{PEG}-\mathrm{Cys}$ and $9 \mathrm{R}$ was confirmed by gel electrophoresis. Figure 1A shows that DG-PEG-Cys-9R (a) and $\mathrm{H}_{3} \mathrm{CO}-\mathrm{PEG}-\mathrm{Cys}-9 \mathrm{R}$ (c) had a higher molecular weight, confirming their successful linkage.

The FTIR spectra of DG displayed a $3291 \mathrm{~cm}^{-1}$ for O-H; C-O for $1034 \mathrm{~cm}^{-1}$. Moreover, the FTIR spectrum of HOOC-PEG-NH $\mathrm{N}_{2}$ revealed that the emerging peak at $1111 \mathrm{~cm}^{-1}$ was the C-O-C in PEG, and the peak at $2885 \mathrm{~cm}^{-1}$ was attributed to C-H in PEG; the peak at $1734 \mathrm{~cm}^{-1}$ was due to the presence of $\mathrm{C}=\mathrm{O}$ in PEG. After the reaction of DG with HOOC-PEG-NH $\mathrm{N}_{2}$, the peaks at $3329 \mathrm{~cm}^{-1}$ and $1577 \mathrm{~cm}^{-1}$ could be attributed to $\mathrm{N}-\mathrm{H}$, and the peak at the $1627 \mathrm{~cm}^{-1}$ was assigned to $\mathrm{C}=\mathrm{O}$, indicating the formation of amide in DG-PEG. After the reaction of Cys with DG-PEG, the peak could be found at $1629 \mathrm{~cm}^{-1}$, which could be attributed to $C=O$. Moreover the $1572 \mathrm{~cm}^{-1}$ and $3330 \mathrm{~cm}^{-1}$ were assigned to $\mathrm{N}-\mathrm{H}$, which indicated the successful formation of amide in DG-PEG-Cys. Compared to the FTIR spectrum (Figure 1B) of free GNS, 9R/DG-GNS displayed a $1085 \mathrm{~cm}^{-1}$ stretching band for 
C-O-C of PEG; $1685 \mathrm{~cm}^{-1}$ for the $\mathrm{C}=\mathrm{O}$ of the amido bond; $3328 \mathrm{~cm}^{-1}$ as the main overlapping peak on the stretching band for N-H of the amido bond; and $2928 \mathrm{~cm}^{-1}$ for the $\mathrm{CH}_{2}$ of PEG, indicating the formation of 9R/DG-GNS. The FTIR spectrum of TSL revealed that the emerging peak at $1092 \mathrm{~cm}^{-1}$ was the stretching band for C-O-C of DSPE-PEG in TSL; the peaks at $2919 \mathrm{~cm}^{-1}$ and $2850 \mathrm{~cm}^{-1}$ were attributed to the presence of methylene and methyl groups in the PEG molecules; and the peak at $1738 \mathrm{~cm}^{-1}$ was due to the presence of DPPC in the TSL. The FTIR spectra of TSL-(9R/DG-GNS) showed that $3419 \mathrm{~cm}^{-1}$ was an overlapping peak on the symmetrical stretching vibration of the O-H of DG and the N-H of the amido bond; while the peaks at $2918 \mathrm{~cm}^{-1}$ and $2850 \mathrm{~cm}^{-1}$ were attributed to the presence of methylene and methyl groups in the PEG molecules. The peak at $1739 \mathrm{~cm}^{-1}$ was attributed to the presence of DPPC in the PTX-TSL. These results indicate that the TSL was attached to the surface of 9R/DG-GNS, confirming the successful construction of TSL-(9R/DG-GNS).

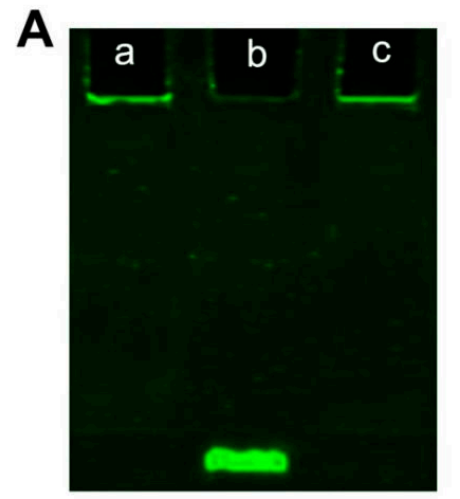

a: DG-PEG-Cys-9R

b: $9 R$

C: H3CO-PEG-Cys-9R

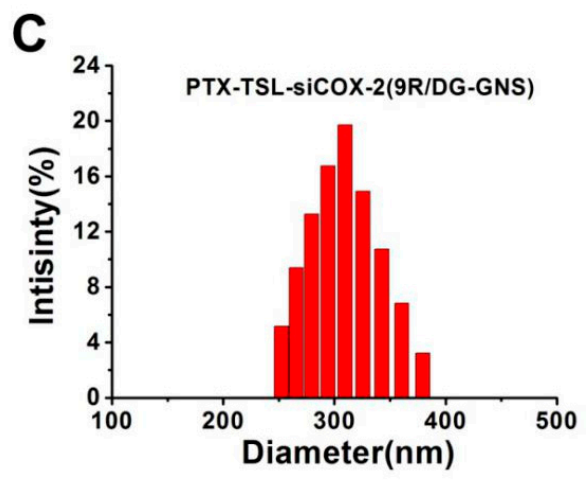

B

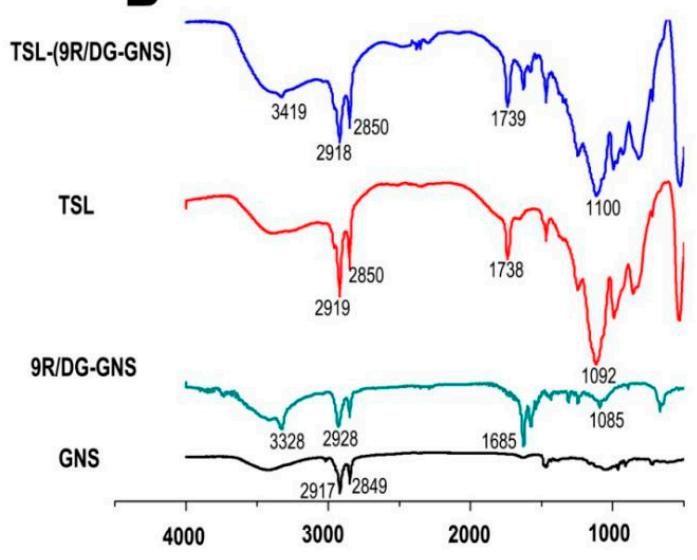

D

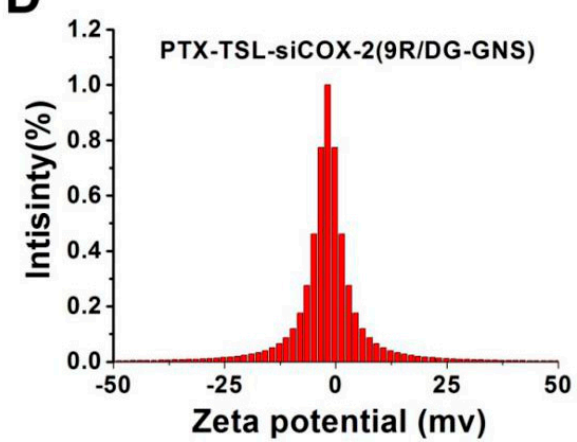

Figure 1. (A) SDS-PAGE of DG-PEG-Cys-9R (a), 9R (b) and $\mathrm{H}_{3} \mathrm{CO}-\mathrm{PEG}-\mathrm{Cys}-9 \mathrm{R}$ (c). (B) FTIR spectra of GNS, 9R/DG-GNS, TSL and TSL-9R/DG-GNS; The particle size (C) and zeta potential (D) histograms of PTX-TSL-siCOX-2 (9R/DG-GNS).

\subsection{Particle Size, Zeta Potentials, and Morphology of the Nanocarriers}

The particle sizes of GNS, 9R-GNS, 9R/DG-GNS, siCOX-2(9R-GNS), siCOX-2(9R/DG-GNS), PTX-TSL and PTX-TSL-siCOX-2 (9R/DG-GNS) were $57.23 \pm 3.42 \mathrm{~nm}, 89.41 \pm 5.53 \mathrm{~nm}, 199.12 \pm 3.91 \mathrm{~nm}$, $203.26 \pm 6.21 \mathrm{~nm}, 231.48 \pm 5.27 \mathrm{~nm}, 93.56 \pm 5.17 \mathrm{~nm}$ and $293.93 \pm 3.21 \mathrm{~nm}$, respectively (Figure 1C, Table 1). The functionalization of 9R, DG and PTX-TSL on the surface of GNS explained the increased size of the hybrid nanoparticles in aqueous solution. The zeta potentials of GNS, 9R-GNS, 9R/DG-GNS, siCOX-2(9R-GNS), siCOX-2(9R/DG-GNS), PTX-TSL and PTX-TSL-siCOX-2(9R/DG-GNS) were $0.12 \pm 0.17 \mathrm{mV}, 19.79 \pm 0.16 \mathrm{mV}, 10.85 \pm 0.25 \mathrm{mV}, 0.26 \pm 0.27 \mathrm{mV}, 0.16 \pm 0.62 \mathrm{mV},-1.78 \pm 0.41 \mathrm{mV}$ and $-2.47 \pm 0.22 \mathrm{mV}$, respectively (Figure $1 \mathrm{D}$, Table 1 ). The $9 \mathrm{R}$ provided a positive surface charge and could adsorb negative siCOX-2. PEG modifications shielded the positive charge of GNS and 9R, 
which helped reduce the toxicity of the co-delivery system. The PDI of each sample group was $\leq 0.3$, demonstrating an improved distribution of the sample particle sizes.

Table 1. The hydrodynamic diameters and zeta potentials of nanoparticles. Values are expressed as mean $\pm \operatorname{SD}(n=3)$.

\begin{tabular}{cccc}
\hline Sample & $\begin{array}{c}\text { Hydrodynamic } \\
\text { Diameter }(\mathbf{n m})\end{array}$ & Polydispersity & Zeta Potential (mV) \\
\hline GNS & $57.23 \pm 3.42$ & $0.23 \pm 0.02$ & $0.12 \pm 0.17$ \\
9R-GNS & $89.41 \pm 5.53$ & $0.25 \pm 0.02$ & $19.79 \pm 0.16$ \\
9R/DG-GNS & $199.12 \pm 3.91$ & $0.21 \pm 0.03$ & $10.85 \pm 0.25$ \\
siCOX-2(9R-GNS) & $203.26 \pm 6.21$ & $0.19 \pm 0.02$ & $0.26 \pm 0.27$ \\
siCOX-2(9R/DG-GNS) & $231.48 \pm 5.27$ & $0.17 \pm 0.03$ & $0.16 \pm 0.62$ \\
PTX-TSL & $93.56 \pm 5.17$ & $0.13 \pm 0.01$ & $-1.78 \pm 0.41$ \\
PTX-TSL-siCOX-2(9R/DG-GNS) & $293.93 \pm 3.21$ & $0.12 \pm 0.04$ & $-2.47 \pm 0.22$ \\
\hline
\end{tabular}

GNS composite carriers were well dispersed as individual nanoparticles and star-shaped based on TEM images (Figure 2). The morphological features of 9R-GNS, 9R/DG-GNS and siCOX-2(9R/DG-GNS) did not differ from GNS. However, the thin film of PTX-TSL was clearly evident on the surface of GNS complexes after modification. The morphological features of PTX-TSL are shown in Figure 2F, in which a round and relatively uniform distribution was observed. It is worth mentioning that the TEM sizes of GNS composite carriers were measured in a dry state, which probably distorted the real sizes and sharpness. However, the hydrodynamic diameter is the real diameter under hydrated conditions that was larger than those observed by TEM. This phenomenon is commonly found in previous report [51,52].
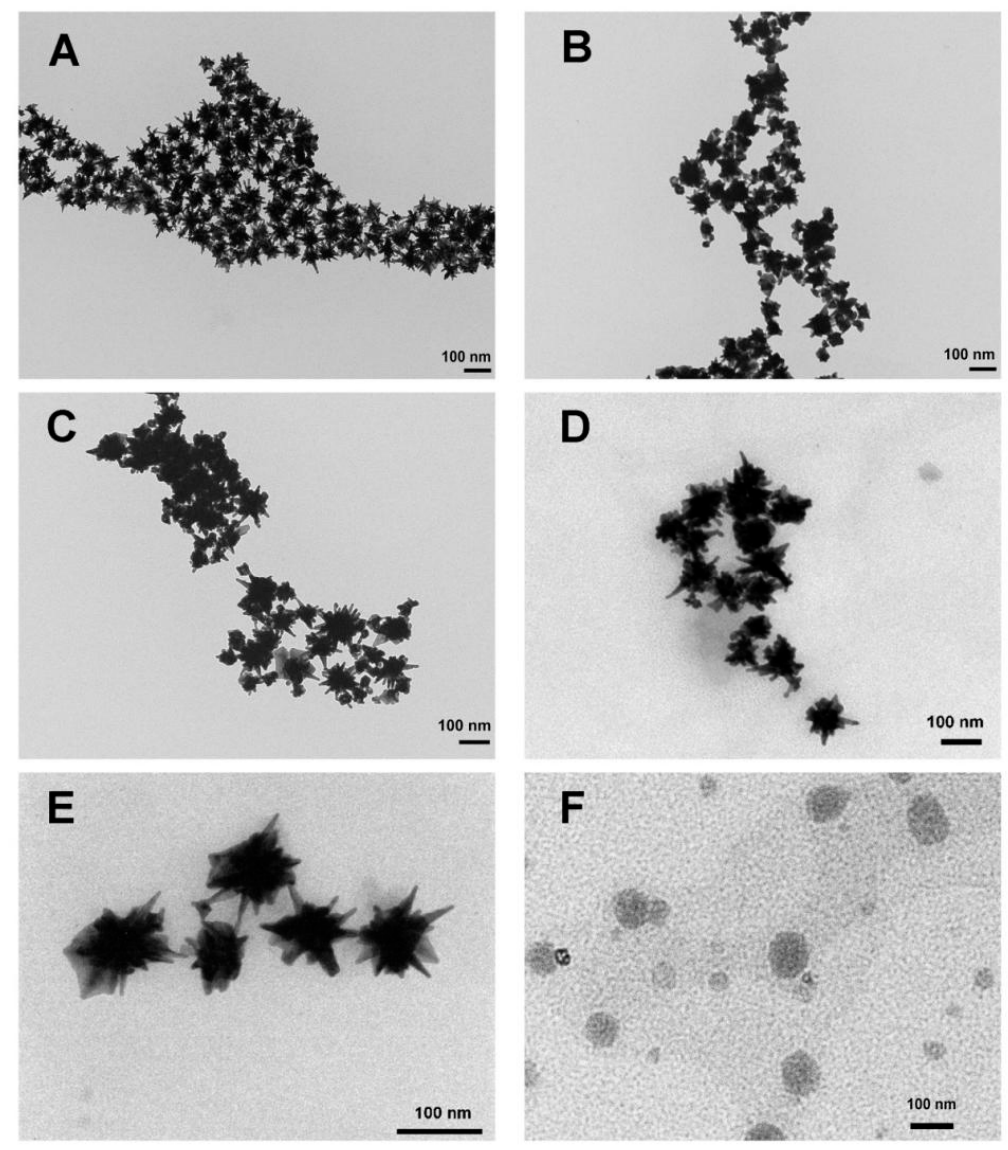

Figure 2. TEM images of GNS (A), 9R-GNS (B), 9R/DG-GNS (C), siCOX-2(9R/DG-GNS) (D), PTX-TSL-siCOX-2(9R/DG-GNS) (E) and PTX-TSL (F). 


\subsection{Spectral Identification and Photothermal Effects of the Nanocarriers}

UV-VIS-NIR absorption spectra are shown in Figure 3A. The maximum UV-VIS-NIR absorption peaks of GNS, 9R-GNS, 9R/DG-GNS, siCOX-2(9R-GNS), siCOX-2(9R/DG-GNS) and PTX-TSL-siCOX-2(9R/DG-GNS) were $785 \mathrm{~nm}, 792 \mathrm{~nm}, 796 \mathrm{~nm}, 810 \mathrm{~nm}, 815 \mathrm{~nm}$ and $825 \mathrm{~nm}$, respectively. No absorption peak was observed near $808 \mathrm{~nm}$ in the non-GNS group (Figure S2). The UV-VIS-NIR absorption peaks displayed a red-shift with no changes in peak width. This confirmed that the red-shift of the UV-VIS-NIR absorption peaks was related to their enhanced particle size after the chemical modification of GNS.
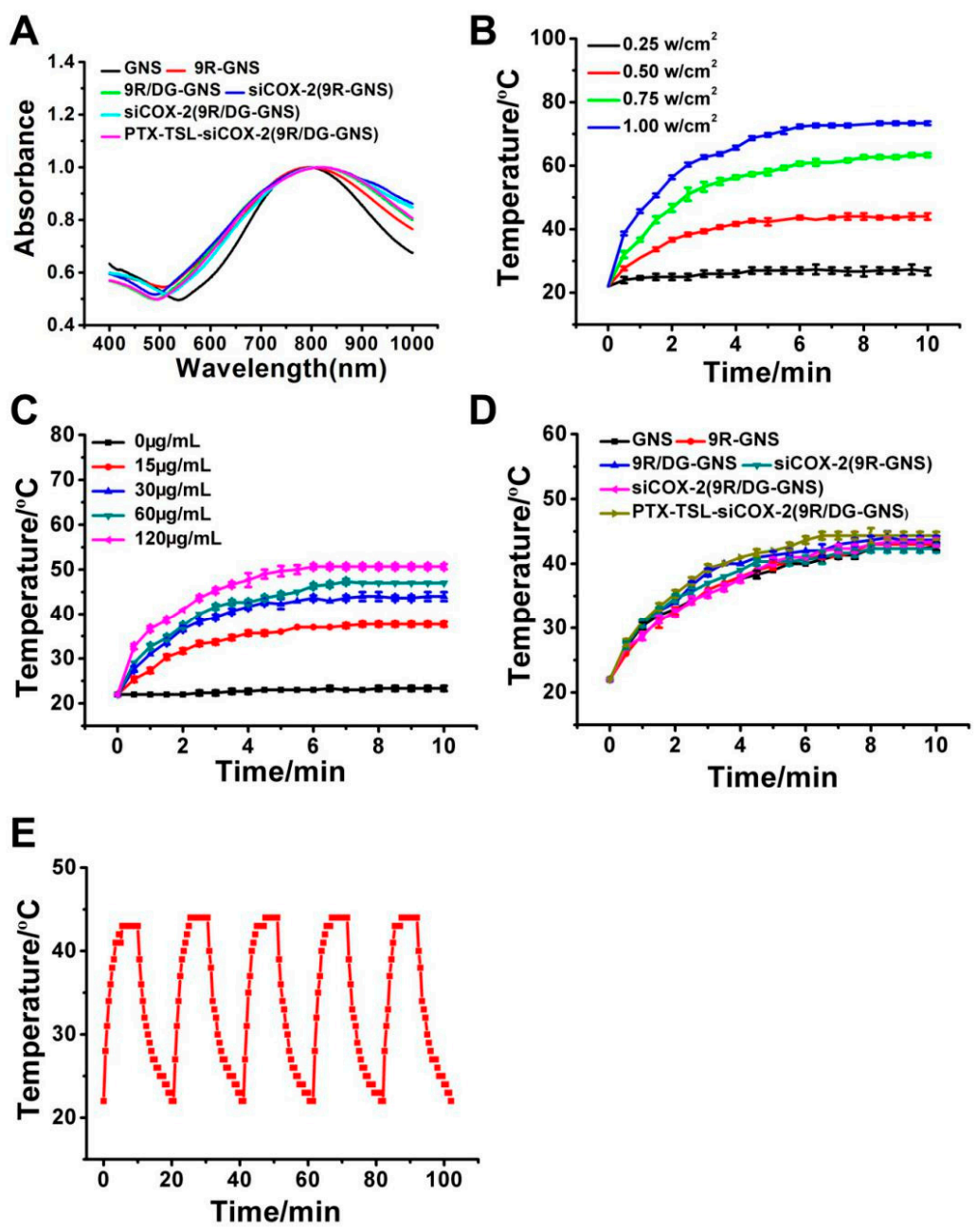

Figure 3. (A) UV-VIS-NIR absorption spectrum of GNS, 9R-GNS, 9R/DG-GNS, siCOX-2(9R-GNS), siCOX-2(9R/DG-GNS) and PTX-TSL-siCOX-2(9R/DG-GNS); (B) Density-dependent temperature increase of PTX-TSL-siCOX-2(9R/DG-GNS) $(30 \mu \mathrm{g} / \mathrm{mL})$ in PBS solution under $808 \mathrm{~nm}$ laser irradiation. (C) Photothermal heating curves of PTX-TSL-siCOX-2(9R/DG-GNS) solution with different concentrations upon $808 \mathrm{~nm}$ laser irradiation at a power density of $0.5 \mathrm{w} / \mathrm{cm}^{2}$. (D) Temperature variation curve of GNS, 9R-GNS, 9R/DG-GNS, siCOX-2(9R-GNS), siCOX-2(9R/DG-GNS) and PTX-TSL-siCOX-2(9R/DG-GNS) after $808 \mathrm{~nm}$ laser irradiation $(n=3)$. (E) Recycling heating profile of PTX-TSL-siCOX-2(9R/DG-GNS) solution $(30 \mu \mathrm{g} / \mathrm{mL})$ under $808 \mathrm{~nm}$ laser irradiation at a power density of $0.5 \mathrm{w} / \mathrm{cm}^{2}$ for five laser on/off cycles.

As displayed in Figure 3B, PTX-TSL-siCOX-2(9R/DG-GNS) $(30 \mu \mathrm{g} / \mathrm{mL})$ increased temperature from 26.6 to $73.3^{\circ} \mathrm{C}$, irradiated with an $808 \mathrm{~nm}$ laser at $0.25-1.00 \mathrm{w} / \mathrm{cm}^{2}$. Figure $3 \mathrm{C}$ shows that temperature validations of PTX-TSL-siCOX-2(9R/DG-GNS) dispersion were from 23.3 to $50.6^{\circ} \mathrm{C}$ under the concentration of $0-120 \mu \mathrm{g} / \mathrm{mL}$ with a laser at $0.5 \mathrm{w} / \mathrm{cm}^{2}$. As shown in Figures 3D and S3, there 
was no apparent temperature increase in the negative control groups (9R, DG, HOOC-PEG-NH2, 9R-Cys-PEG-OCH ${ }_{3}$ and 9R-Cys-PEG-DG) after NIR laser irradiation $\left(0.5 \mathrm{~W} / \mathrm{cm}^{2}\right)$ for $10 \mathrm{~min}$. However, the temperature curves of GNS composite carriers revealed that further modification of targeted ligand caused a minimal impairment on the photothermal effect of GNS. Moreover, the photostability of PTX-TSL-siCOX-2(9R/DG-GNS) was performed under $808 \mathrm{~nm}$ laser every 20 min over 5 on/off cycles (Figure 3E). Apparently, the photothermal conversion effect of PTX-TSL-siCOX-2(9R/DG-GNS) demonstrated its favorable stability and promising potential as a photothermal therapy agent for tumor therapy. To avoid excessive laser power and unnecessary damage to normal tissue in subsequent animal experiments, an NIR laser at $0.5 \mathrm{w} / \mathrm{cm}^{2}$ was chosen. Then, the therapeutic temperature of $43{ }^{\circ} \mathrm{C}$ for the following anti-tumor experiments was reached with PTX-TSL-siCOX-2(9R/DG-GNS) $(30 \mu \mathrm{g} / \mathrm{mL})$ under $0.5 \mathrm{w} / \mathrm{cm}^{2}$.

\subsection{Analysis of the siCOX-2 Encapsulation}

The siCOX-2 binding abilities of carriers based on 9R-GNS or 9R/DG-GNS were analyzed by gel shift assay [53,54]. As shown in Figure 4A, the composite nanoparticle of GNS complexes (9R-GNS, 9R/DG-GNS) and siCOX-2 was prevented from moving towards the positive electrode in $4 \%$ agarose gels. When siCOX-2 was combined with the nanocarriers at the correct ratio, the positively charged ligand neutralized the negative charge of siCOX-2, and its movement towards the positive electrode was inhibited [55]. Then, the GNS complex was coated with PTX-TSL by mercapto coordination, which protects siCOX-2 and increases its stability. When the GNS core was coated by PTX-TSL, we found that the construction of PTX-TSL-siCOX-2(9R/DG-GNS) can be formed and optimized at the molar ratio of (molar ratio of siCOX-2/PTX-TSL-(9R/DG-GNS) was 1:40 or 1:60).
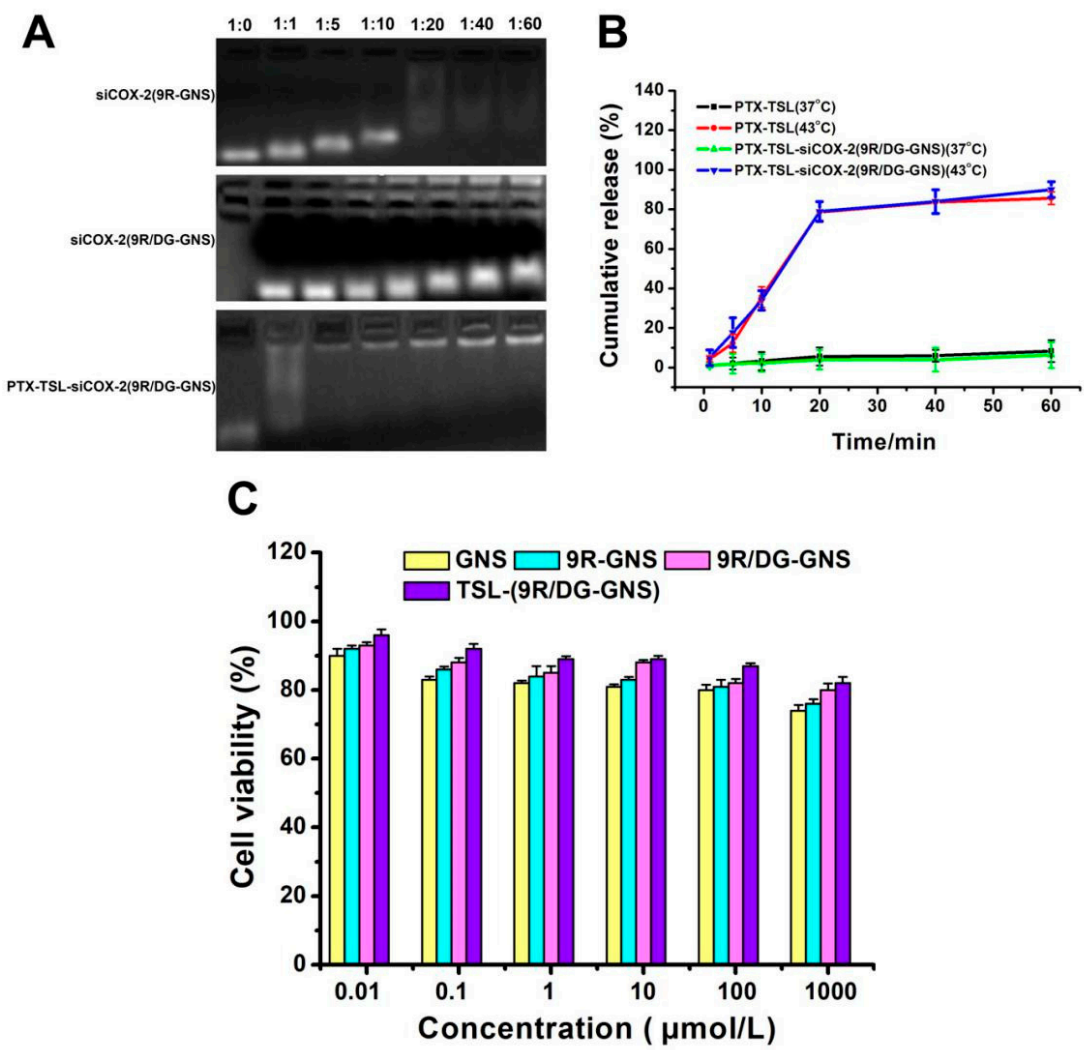

Figure 4. (A) Binding ability of 9R-GNS, 9R/DG-GNS, PTX-TSL-(9R/DG-GNS) and siCOX-2 mixtures at different molar ratios (1:0, 1:1, 1:5, 1:10, 1:20, 1:40 \& 1:60). (B) Release curves of PTX-TSL ( $37^{\circ} \mathrm{C}$ and $\left.43^{\circ} \mathrm{C}\right)$ and PTX-TSL-siCOX-2(9R/DG-GNS) $\left(37^{\circ} \mathrm{C}\right.$ and $\left.43^{\circ} \mathrm{C}\right)(n=3) .(\mathrm{C})$ Cytotoxicity analysis of GNS, 9R-GNS, 9R/DG-GNS and TSL-(9R/DG-GNS) in HUVECs at different concentrations. Data represent the mean $\pm \operatorname{SD}(n=3)$. 


\subsection{Detection of Drug Loading and Release Capacity of PTX-TSL}

The PTX peak areas of the concentration gradients were determined by HPLC. The PTX concentration was used as an abscissa and the peak area was used as the ordinate for standard curve construction: $y=26111 \mathrm{x} \pm 26707\left(R^{2}=0.9986\right)$. The drug loading and encapsulation efficiency of PTX-TSL-(9R/DG-GNS) was calculated as $7.2 \% \pm 1.19$ and $92.98 \% \pm 1.07$, respectively.

The phase changes of the temperature sensitive liposomes by DSC were $42.6^{\circ} \mathrm{C}$. Both $37^{\circ} \mathrm{C}$ and $43{ }^{\circ} \mathrm{C}$ were selected as the drug release conditions. As shown in Figure $4 \mathrm{~B}$, the liposomes were stable at $37^{\circ} \mathrm{C}$ and the released PTX-TSL and PTX-TSL-siCOX-2(9R/DG-GNS) were $\leq 10 \%$ after 60 $\mathrm{min}$. This was primarily due to the temperature being below the phase transition temperature $(\mathrm{Tm})$. The temperature-sensitive liposome membranes were in a densely packed colloidal state through which drug diffusion was low. Surprisingly, PTX-TSL and PTX-TSL-siCOX-2(9R/DG-GNS) had rapid release kinetics in the first 20 min which remained at $~ 80 \%$ under heating conditions $\left(43^{\circ} \mathrm{C}\right.$ ) (Figure $4 \mathrm{~B}$ ). This was because at $42{ }^{\circ} \mathrm{C}$, the outer membranes underwent phase transition, became permeable, and the encapsulated drug was rapidly released. Temperatures of $43{ }^{\circ} \mathrm{C}$ were slightly higher than the phase transition temperatures $\left(42.6^{\circ} \mathrm{C}\right)$ of temperature-sensitive liposomes, meaning that the release was faster $[56,57]$.

\subsection{Stability of the Co-Delivery System PTX-TSL (siCOX-2(9R/DG-GNS))}

To assess the stability of PTX-TSL-siCOX-2(9R/DG-GNS), samples were measured over different time periods at $4{ }^{\circ} \mathrm{C}$. The particle sizes were $294.90 \pm 7.21 \mathrm{~nm}, 294.75 \pm 9.04 \mathrm{~nm}$, and $295.63 \pm 9.68 \mathrm{~nm}$, and the PDI values were $0.14 \pm 0.03,0.16 \pm 0.05,0.17 \pm 0.06$, respectively. The minimal changes on particle size and PDI of PTX-TSL-siCOX-2(9R/DG-GNS) indicated that the co-delivery system was stable and did not aggregate at $4{ }^{\circ} \mathrm{C}$ for three weeks.

\subsection{In Vitro Formulation Compatibility}

MTT assay was used to evaluate the cytotoxicity of free GNS and GNS complexes on HUVECs. As shown in Figure 4C, the viability of the HUVECs after treatment with GNS, 9R-GNS, 9R/DG-GNS and TSL-(9R/DG-GNS) was approximately $72 \%, 76 \%, 80 \%$ and $82 \%$ at the highest concentration $(1000 \mu \mathrm{mol} / \mathrm{L})$, respectively. Notably, the viability of cells treated by TSL-(9R/DG-GNS) at any other doses $(0.01,0.1,1,10,100 \mu \mathrm{mol} / \mathrm{L})$ were all $\geq 90 \%$. Notably, the GNS complex displayed improved biocompatibility after modification with TSL. TSL could shield the positive charge of $9 \mathrm{R}$ and the toxic components of GNS, which enhanced biocompatibility.

\subsection{In Vitro Cellular Uptake}

We evaluated the cellular uptake of siCOX-2 and GNS complexes in paclitaxel-resistant HepG2 cells (HepG2/PTX cells) using confocal laser-scanning microscopy (CLSM) (Figure 5). Fluorescence imaging (Figure 5A) indicated that siCOX-2(GNS) was unable to enter HepG2/PTX cells. siCOX-2(9R-GNS) could partially penetrate after $4 \mathrm{~h}$ incubation, while the levels of siCOX-2(9R/DG-GNS) entry were high, particularly under heating conditions $\left(43{ }^{\circ} \mathrm{C}, 15 \mathrm{~min}\right)$. Only small amounts of PTX-TSL-siCOX-2(9R/DG-GNS) entered the cells in the absence of laser irradiation. However, PTX-TSL-siCOX-2(9R/DG-GNS) under heating conditions displayed high levels of cell entry, evidenced by the increased CLSM fluorescence intensity. This was further confirmed by the quantitative analysis of the averaged fluorescent intensities of each sample at a $4 \mathrm{~h}$ incubation time (Figure 5B). A significantly lower intracellular fluorescence intensity was found in the cells treated with the siCOX-2(GNS), compared to those of other nanoparticles. siCOX-2(9R-GNS) partially entered cells, which was related to the transmembrane effects of $9 \mathrm{R}$. GNS modified with $9 \mathrm{R}$ and DG could be taken up by tumor cells through the targeting effects of DG and the transmembrane effects of $9 \mathrm{R}$. At $43^{\circ} \mathrm{C}$, membrane permeability was higher and the levels of siCOX-2(9R/DG-GNS) entering the cells increased. The levels of endocytosed PTX-TSL-siCOX-2(9R/DG-GNS) were low. This was because the non-laser irradiation 
group of siCOX-2(9R/DG-GNS) was coated with TSL, which had shielding action on DG and 9R. However, when the temperature reached the phase transition temperature of TSL, PTX and internal siCOX-2(9R/DG-GNS) could be released. Hence, PTX-TSL-siCOX-2(9R/DG-GNS) entered cells to significantly higher levels under heating conditions $\left(43^{\circ} \mathrm{C}, 15 \mathrm{~min}\right)$.

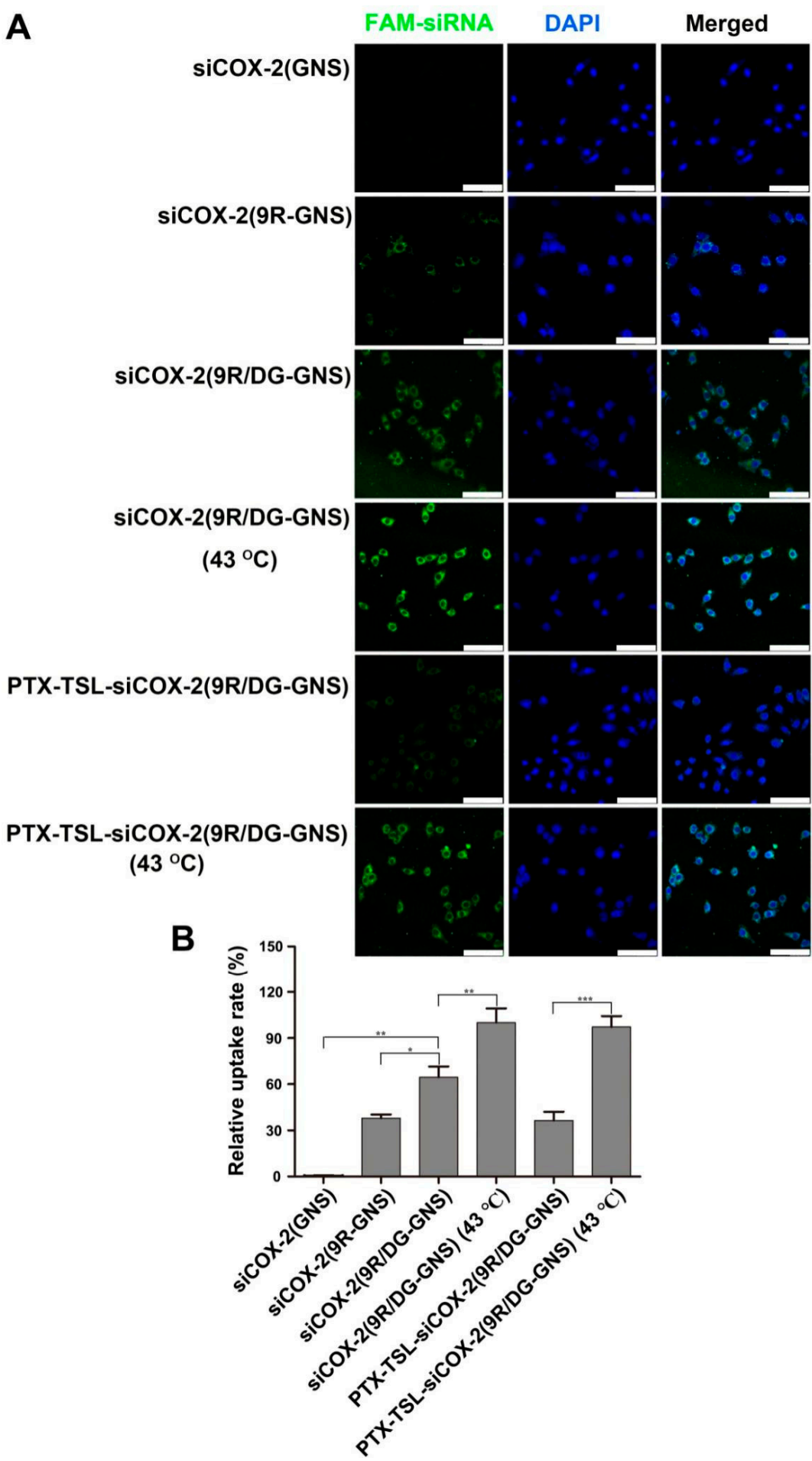

Figure 5. (A) In vitro cellular uptake of siCOX-2(GNS), siCOX-2(9R-GNS), siCOX-2(9R/DG-GNS), siCOX-2(9R/DG-GNS) $\left(43^{\circ} \mathrm{C}\right)$ and PTX-TSL-siCOX-2(9R/DG-GNS) $\left(43^{\circ} \mathrm{C}\right)$ in HepG2/PTX cells after $4 \mathrm{~h}$ incubation observed under laser confocal microscopy. Green: FAM-labeled siRNA; blue: DAPI-labled nucleus. Scale bar: $100 \mu \mathrm{m}$. (B) Quantified cellular uptake in paclitaxel- resistant HepG2 cells (HepG2/PTX cells). Data represent the mean \pm SD. ${ }^{*} p<0.05,{ }^{* *} p<0.01,{ }^{* * *} p<0.001$. 


\subsection{Gene Silencing Efficiency of PTX-TSL-siCOX-2(9R/DG-GNS)}

The gene silencing efficiency of the siCOX-2(GNS) complex in HepG2/PTX cells was assessed by a Western blot analysis. As shown in Figure 6, compared to siCOX-2(GNS) and siCOX-2/9R-GNS groups, COX-2 silencing was higher in the siCOX-2(9R/DG-GNS) group ( $p<0.001$ and $p<0.01$ respectively). Under heating conditions $\left(43^{\circ} \mathrm{C}, 15 \mathrm{~min}\right)$, siCOX-2(9R/DG-GNS) could significantly downregulate the expression of COX-2 expression $(p<0.05)$. This was likely due to the DG targeting effects [58-60], the transmembrane effects of $9 \mathrm{R}$, and increased heat-induced membrane permeability [61,62]. Increased temperatures can lead to increases in cell membrane permeability and enhance the transfection efficiency of gene delivery systems. siCOX-2(9R/DG-GNS) complexes were encapsulated by PTX-TSL but did not downregulate COX-2. COX-2 silencing in HepG2/PTX cells increased after treatment with PTX-TSL-siCOX-2(9R/DG-GNS), most notably at $43^{\circ} \mathrm{C}$. In the presence of heating, TSL membranes were destroyed and siCOX-2(9R/DG-GNS) was exposed, promoting PTX and siCOX-2 release. This explains why after heating, PTX-TSL-siCOX-2(9R/DG-GNS) could significantly silence COX-2 expression.

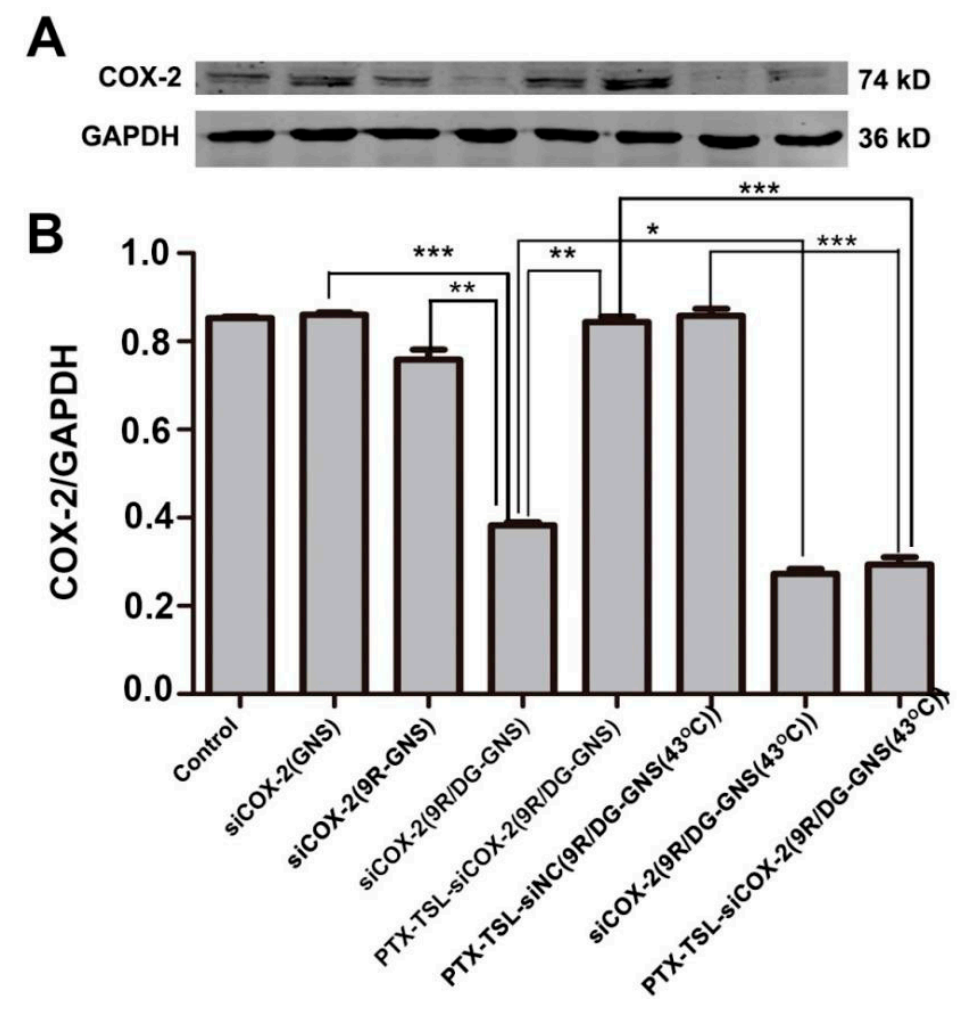

Figure 6. (A) Western blot assessment of COX-2 expression in HepG2/PTX cells following incubation with siCOX-2(GNS), siCOX-2(9R-GNS), siCOX-2(9R/DG-GNS), PTX-TSL-siCOX-2(9R/DG-GNS), PTX-TSL-siNC(9R/DG-GNS), siCOX-2(9R/DG-GNS) $\left(43^{\circ} \mathrm{C}\right)$ and PTX-TSL-siCOX-2(9R/DG-GNS) $\left(43^{\circ} \mathrm{C}\right)$. SiRNA concentration: $50 \mathrm{nM}$. (B) Protein bands were quantified and normalized to GAPDH. ${ }^{*} p<0.05$, ${ }^{* *} p<0.01,{ }^{* * *} p<0.001$ vs. other groups.

\subsection{Effects of PTX-TSL-siCOX-2(9R/DG-GNS) on Cancer Cell Growth}

To assess the effects of PTX-TSL-siCOX-2(9R/DG-GNS), drug-resistant cell growth experiments were performed. Figure 7A shows that increasing siCOX-2 concentrations led to enhanced antitumor effects. Compared to siCOX-2(GNS) and siCOX-2(9R-GNS), siCOX-2(9R/DG-GNS) more potently inhibited HepG2/PTX cell growth $(p<0.05)$. When siCOX-2(9R/DG-GNS) was encapsulated with PTX-TSL for combination therapy, its antitumor effects significantly improved $(p<0.05)$. Moreover, the antitumor effects of each group increased at $43{ }^{\circ} \mathrm{C}(15 \mathrm{~min})$. At the maximum concentration of siCOX-2 (100 nM), the viability of PTX-TSL-siCOX-2(9R/DG-GNS) treated HepG2/PTX cells was as low as $23 \%(p<0.001)$. These enhanced effects were most likely due to the ability of siCOX-2 to reverse 
tumor resistance following heating, which enhanced both transfection efficiencies, gene silencing, and promoting tumor cell apoptosis [63-65].
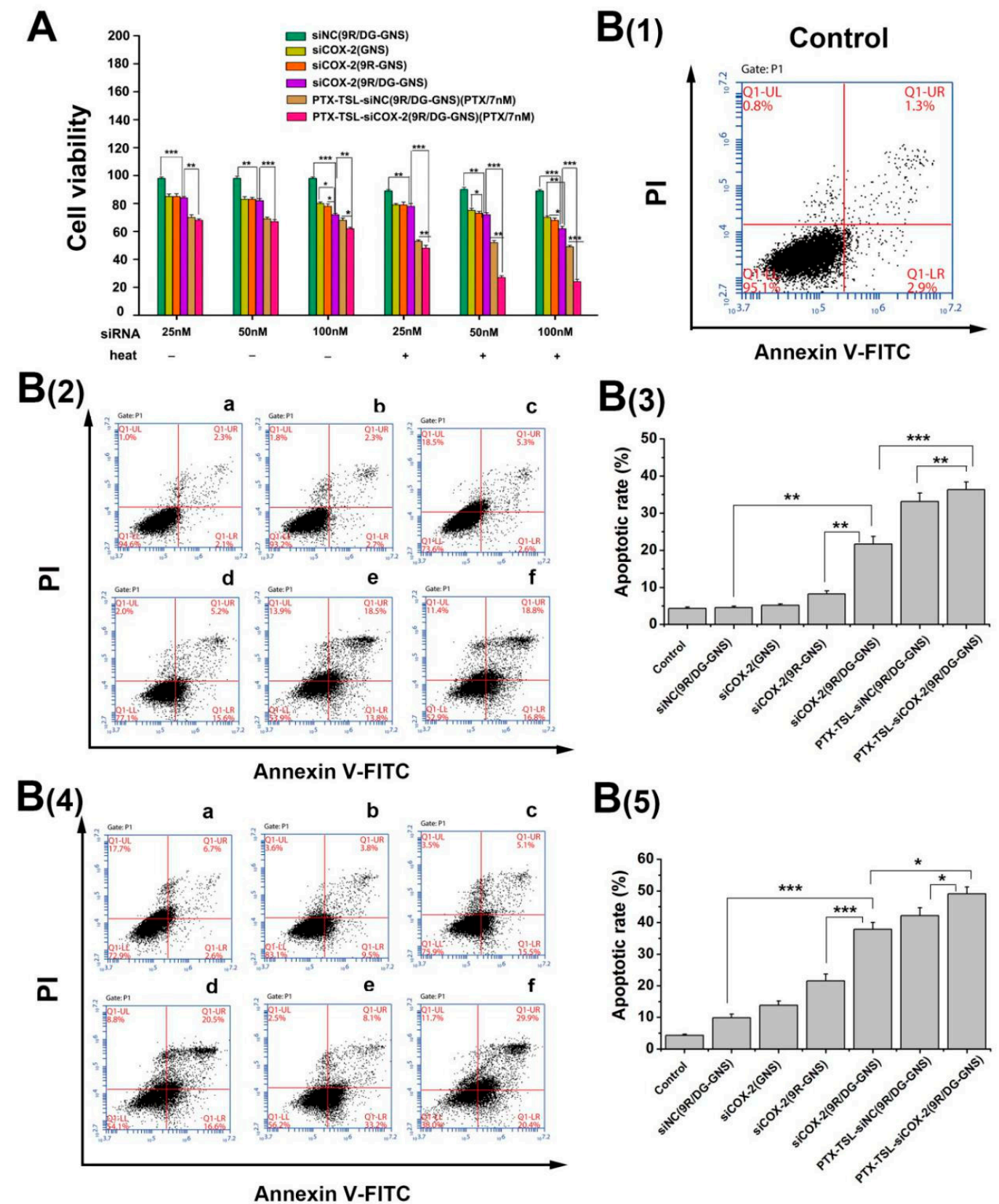

B(5)

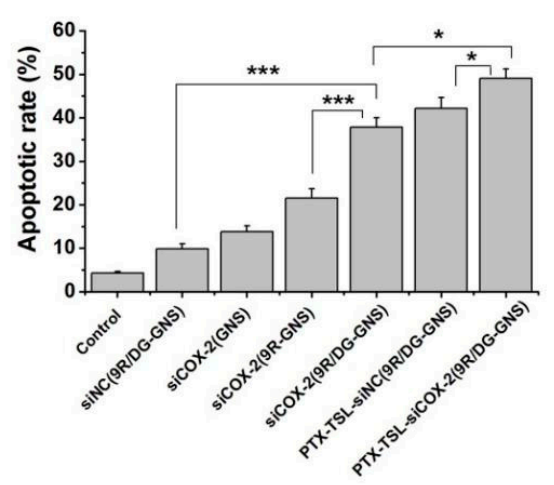

Figure 7. (A) Cell growth assays in HepG2/PTX cells treated with $7 \mathrm{nM}$ PTX; 25, 50 and $100 \mathrm{nM}$ siRNA (siNC and siCOX-2) loaded GNS, 9R-GNS, 9R/DG-GNS and PTX-TSL-(9R/DG-GNS) with or without heating. Data are the mean $\pm \mathrm{SD}(n=3)$. $(\mathbf{B}(1))$ The flow cytometry analysis of non-treated HepG2/PTX cells (control group). (B(2)) Cell apoptotic rates and flow cytometry analysis of HepG2/PTX cells treated with different groups (a: siNC(9R/DG-GNS), b: siCOX-2(GNS), c: siCOX-2(9R-GNS), d: siCOX-2(9R/DG-GNS), e: PTX-TSL-siNC(9R/DG-GNS), and f: PTX-TSL-siCOX-2(9R/DG-GNS)) under $37^{\circ} \mathrm{C}$. $(\mathbf{B}(3))$ Percentage of apoptotic cells under $37^{\circ} \mathrm{C}$, the data are expressed as the mean $\pm \mathrm{SD}(n=3)$. (B(4)) Cell apoptotic rates and flow cytometry analysis of HepG2/PTX cells treated with different groups (a: siNC(9R/DG-GNS), b: siCOX-2(GNS), c: siCOX-2(9R-GNS), d: siCOX-2(9R/DG-GNS), e: PTX-TSL-siNC(9R/DG-GNS), and f: PTX-TSL-siCOX-2(9R/DG-GNS)) under $43^{\circ} \mathrm{C}$. (B(5)) Percentage of apoptotic cells under $43^{\circ} \mathrm{C}$, the data are expressed as the mean $\pm \mathrm{SD}(n=3)$. PTX concentration was $7 \mathrm{nM}$ and siRNA (siNC and siCOX-2) concentration was $50 \mathrm{nM}$. ${ }^{*} p<0.05,{ }^{* *} p<0.01,{ }^{* * *} p<0.001$. 
Co-delivery systems combining gene therapeutic agents (miRNA and siRNA) and anti-tumor drug are highlighted as effective and innovative systems for overcoming multidrug resistance (MDR) [66,67]. Physical approaches, such as the combination of drug with photodynamic/ultrasound/thermal therapies to overcome MDR have also been focused on [68-71]. In contrast, the nanoplatform based gene-, chemoand photothermal combination therapy for reversing MDR was rarely studied [72]. Our research shows that chemo- and gene- co-delivery system delivered with hybrid gold nanostars coated by temperature sensitive liposomes (PTX-TSL-siCOX-2(9R/DG-GNS)) could improve paclitaxel-resistance in hepatic carcinoma in combination with thermal therapy.

\subsection{Cell Apoptosis}

Annexin V-FITC/PI double staining was performed to determine the apoptosis of HepG2/PTX cells treated by different nanoparticles. As shown in Figure 7B, compared to siNC(9R/DG-GNS) group, the cells treated with siCOX-2(9R/DG-GNS) under $37^{\circ} \mathrm{C}$ displayed a significantly higher rate of apoptosis, $\sim 20.8 \%$ (sum of late apoptosis percentage (Q2) and early apoptosis percentage (Q3)). These results can be attributed to the combination of 9R/DG-GNS and siCOX-2. Compared to siCOX-2(9R/DG-GNS) group, the cells treated with PTX-TSL-siCOX-2(9R/DG-GNS) also displayed notable apoptosis, with apoptosis rates of $\sim 34.8 \%$. These results can be mostly attributed to the chemotherapeutic effects of PTX and the existing of TSL, which can protect the stability of the encapsulated siCOX-2. In addition, the cells treated with PTX-TSL-siCOX-2(9R/DG-GNS) followed by $43{ }^{\circ} \mathrm{C}$ heating for 15 $\min$ had apoptosis rate increased to $\sim 47 \%$. Upon heating, both the increased temperature and the enhanced drug release contributed to the induction of cell apoptosis. These results confirm that the hyperthermia combined with chemotherapy and gene therapy could significantly increase the cell growth inhibition rate.

\section{Conclusions}

In summary, we successfully prepared siCOX-2 loaded GNS composite nanoparticles siCOX-2(9R/DG-GNS). The PTX-TSL-siCOX-2(9R/DG-GNS) co-delivery system was further constructed. The delivery system has many advantages, including rapid release and rapid uptake by tumor cells under elevated temperatures. The results of the anti-tumor drug resistant assays showed that siCOX-2 could effectively overcome resistance to PTX. Additionally, drug-resistant cancer cells could be targeted by the photothermal conversion effects of GNS. Therefore, the PTX-TSL-siCOX-2(9R/DG-GNS) system holds promise for the treatment of anti-tumor drug resistance.

Supplementary Materials: The following are available online at http://www.mdpi.com/1999-4923/11/12/683/s1, Figure S1: ${ }^{1} \mathrm{HNMR}$ spectra of DG, HOOC-PEG-NH $\mathrm{N}_{2}$, DG-PEG-Cys, $\mathrm{H}_{3} \mathrm{CO}-\mathrm{PEG}-\mathrm{NH}_{2}$, and $\mathrm{H}_{3} \mathrm{CO}-\mathrm{PEG}-\mathrm{Cys}$. DG: 2-Amino-2-deoxy-D-glucose; Cys: Cysteine, Figure S2: FTIR spectra of DG, HOOC-PEG-NH2, DG-PEG and DG-PEG-Cys; Figure S3: Tempetature variation curves of 9R, DG, HOOC-PEG-NH 2 , 9R/DG, GNS and 9R/DG-GNS solution under the continuous NIR laser irradiation $\left(808 \mathrm{~nm}, 0.5 \mathrm{~W} / \mathrm{cm}^{2}\right)$ for $10 \mathrm{~min}(n=3)$; Figure S4: Ultraviolet absorption spectrum of PTX-TSL.

Author Contributions: D.Z. and H.G. designed the idea and drew up the whole project. W.H., Y.G. and L.S. performed the synthesis, characterization, data analysis. Q.L. and X.L. facilitated with methodology. H.Z. wrote the manuscript and revised the manuscript.

Funding: This research was funded by the National Natural Science Foundation of China $(81660681,81202467)$, Natural Science Foundation of Guangxi Province of China (2018GXNSFAA294080), Guangxi First-class Discipline Project for Pharmaceutical Sciences (GXFCDP-PS-2018), Joint Cultivation Base of Inovation \& Entrepreneurship for Pharmaceutical Postgraduates (20170703) and Postgraduate Research \& Practice Innovation Program of Jiangsu Province (KYCX18_2436).

Acknowledgments: The authors thank Yanjiang Chen of University of Melbourne, for her support in the revise and polish of the manuscript.

Conflicts of Interest: The authors declare no conflict of interest. 


\section{References}

1. Rowinsky, E.K. The development and clinical utility of the taxane class of antimicrotubule chemotherapy agents. Annu. Rev. Med. 1997, 48, 353-374. [CrossRef] [PubMed]

2. Gan, Y.; Wientjes, M.G.; Schuller, D.E.; Au, J.L. Pharmacodynamics of Taxol in human head and neck tumors. Cancer Res. 1996, 56, 2086-2093. [PubMed]

3. Parekh, H.; Wiesen, K.; Simpkins, H. Acquisition of taxol resistance via P-glycoprotein- and non-P-glycoprotein-mediated mechanisms in human ovarian carcinoma cells. Biochem. Pharmacol. 1997, 53, 461-470. [CrossRef]

4. Huang, M.; Liu, G. The study of innate drug resistance of human hepatocellular carcinoma Bel cell line. Cancer Lett. 1999, 135, 97-105. [CrossRef]

5. Chabner, B.A.; Wilson, W. Reversal of multidrug resistance. J. Clin. Oncol. 1991, 9, 4-6. [CrossRef] [PubMed]

6. Luo, D.; Cheng, S.C.; Xie, H.; Xie, Y. Chemosensitivity of Human Hepatocellular Carcinoma Cell Line QGY-7703 is Related to Bcl-2 Protein Levels. Tumour Biol. 1999, 20, 331-340. [CrossRef] [PubMed]

7. Ye, T.; Xu, W.; Shi, T.; Yang, R.; Yang, X.; Wang, S.; Pan, W. Targeted delivery of docetaxel to the metastatic lymph nodes: A comparison study between nanoliposomes and activated carbon nanoparticles. Asian J. Pharm. Sci. 2015, 10, 64-72. [CrossRef]

8. Jang, S.H.; Wientjes, M.G.; Au, J.L. Kinetics of P-Glycoprotein-Mediated Efflux of Paclitaxel. J. Pharmacol. Exp. Ther. 2001, 298, 1236-1242.

9. Kondratov, R.V.; Komarov, P.G.; Becker, Y.; Ewenson, A.; Gudkov, A.V. Small molecules that dramatically alter multidrug resistance phenotype by modulating the substrate specificity of P-glycoprotein. Proc. Natl. Acad. Sci. USA 2001, 98, 14078-14083. [CrossRef]

10. Penson, R.T.; Oliva, E.; Skates, S.J.; Glyptis, T.; Fuller, A.F.; Goodman, A.; Seiden, M.V. Expression of multidrug resistance-1 protein inversely correlates with paclitaxel response and survival in ovarian cancer patients: a study in serial samples. Gynecol Oncol. 2004, 93, 98-106. [CrossRef]

11. Orr, G.A.; Verdier-Pinard, P.; Mcdaid, H.; Horwitz, S.B. Mechanisms of Taxol resistance related to microtubules. Oncogene 2003, 22, 7280-7295. [CrossRef] [PubMed]

12. Tabuchi, Y.; Matsuoka, J.; Gunduz, M.; Imada, T.; Ono, R.; Ito, M.; Motoki, T.; Yamatsuji, T.; Shirakawa, Y.; Takaoka, M.; et al. Resistance to paclitaxel therapy is related with Bcl-2 expression through an estrogen receptor mediated pathway in breast cancer. Int. J. Oncol. 2009, 34, 313-319. [PubMed]

13. Agarwal, R.; Kaye, S.B. Ovarian cancer: Strategies for overcoming resistance to chemotherapy. Nat. Rev. Cancer 2003, 3, 502-516. [CrossRef] [PubMed]

14. Hortobagyi, G.N.; Ueno, N.T.; Xia, W. Cationic liposome mediated EIA gene trenser to human breast and ovarian cancer cells and its biologie effects a phase I clinical trial. Clin. Oncol. 2001, 19, 3422-3433. [CrossRef] [PubMed]

15. Ishida, O.; Maruyama, K.; Yanagie, H.; Eriguchi, M.; Iwatsuru, M. Targeting Chemotherapy to Solid Tumors with Long-circulating Thermosensitive Liposomes and Local Hyperthermia. Jpn. J. Cancer Res. 2000, 91, 118-126. [CrossRef]

16. Lindner, L.H.; Eichhorn, M.E.; Eibl, H.; Teichert, N.; Schmitt-Sody, M.; Issels, R.D.; Dellian, M. Novel Temperature-Sensitive Liposomes with Prolonged Circulation Time. Clin. Cancer Res. 2004, 10, 2168-2178. [CrossRef]

17. Ono, A.; Takeuchi, K.; Sukenari, A.; Suzuki, T.; Adachi, I.; Ueno, M. Reconsideration of Drug Release from Temperature-Sensitive Liposomes. Biol. Pharm. Bull. 2002, 25, 97-101. [CrossRef]

18. Wells, J.; Sen, A.; Hui, S.W. Localized delivery to CT-26 tumors in mice using thermosensitive liposomes. Int. J. Pharm. 2003, 261, 105-114. [CrossRef]

19. Mulik, R.; Kulkarni, V.; Murthy, R.S. Chitosan-Based Thermosensitive Hydrogel Containing Liposomes for Sustained Delivery of Cytarabine. Drug. Dev. Ind. Pharm. 2009, 35, 49-56. [CrossRef]

20. Chen, J.; Cheng, D.; Li, J.; Wang, Y.; Guo, J.X.; Chen, Z.P.; Cai, B.C.; Yang, T. Influence of lipid composition on the phase transition temperature of liposomes composed of both DPPC and HSPC. Drug. Dev. Ind. Pharm. 2013, 39, 197-204. [CrossRef]

21. Kono, K. Thermosensitive polymer-modified liposomes. Adv. Drug Deliv. Rev. 2001, 3, 307-319. [CrossRef]

22. Needham, D.; Dewhirst, M.W. The Development and Testing of a New Temperature-sensitive Drug Delivery System for the Treatment of Solid Tumors. Adv. Drug Deliv. Rev. 2001, 53, 285-305. [CrossRef] 
23. Karino, T.; Koga, S.; Maeta, M. Experimental studies of the effects of local hyperthermia on blood flow, oxygen pressure and pH in tumors. Jpn. J. Surg. 1988, 18, 276-283. [CrossRef] [PubMed]

24. Gaber, M.H.; Wu, N.Z.; Hong, K.; Huang, S.K.; Dewhirst, M.W.; Papahadjopoulos, D. Thermosensitive liposomes: Extravasation and release of contents in tumor microvascular networks. Int. J. Radiat. Oncol. Biol. Phys. 1996, 36, 1177-1187. [CrossRef]

25. Sau, S.; Agarwalla, P.; Mukherjee, S.; Bag, I.; Sreedhar, B.; Pal-Bhadra, M.; Patra, C.R.; Banerjee, R. Cancer cell-selective promoter recognition accompanies antitumor effect by glucocorticoid receptor-targeted gold nanoparticle. Nanoscale 2014, 6, 6745-6754. [CrossRef] [PubMed]

26. Balakrishnan, S.; Mukherjee, S.; Das, S.; Bhat, F.A.; Raja Singh, P.; Patra, C.R.; Arunakaran, J. Gold nanoparticles conjugated quercetin induces apoptosis via inhibition of EGFR/PI3K/Akt mediated pathway in breast cancer cell lines (MCF-7 and MDA-MB-231). Cell. Biochem. Funct. 2017, 35, 217-231. [CrossRef] [PubMed]

27. Jain, P.K.; Lee, K.S.; El-Sayed, I.H.; El-Sayed, M.A. Calculated absorption and scattering properties of gold nanoparticles of different size, shape, and composition: applications in biological imaging and biomedicine. J. Phys. Chem. B 2006, 110, 7238-7248. [CrossRef]

28. Sau, T.K.; Rogach, A.L.; Jäckel, F.; Klar, T.A.; Feldmann, J. Properties and Applications of Colloidal Nonspherical Noble Metal Nanoparticles. Adv. Mater. 2010, 22, 1805-1825. [CrossRef]

29. Weissleder, R. A clearer vision for in vivo imaging. Nat. Biotechnol. 2001, 19, 316-317. [CrossRef]

30. Wang, S.; Peng, H.; Nie, L.; Xing, R.; Liu, D.; Wang, Z.; Lin, J.; Chen, S.; Niu, G.; Lu, G.; et al. Biomedical Applications: Single Continuous Wave Laser Induced Photodynamic/Plasmonic Photothermal Therapy Using Photosensitizer-Functionalized Gold Nanostars. Adv. Mater. 2013, 25, 3009. [CrossRef]

31. Yuan, H.; Khoury, C.G.; Wilson, C.M.; Grant, G.A.; Bennett, A.J.; Vo-Dinh, T. In vivo particle tracking and photothermal ablation using plasmon-resonant gold nanostars. Nanomedicine 2012, 8, 1355-1363. [CrossRef] [PubMed]

32. Lu, L.; Ai, K.; Ozaki, Y. Environmentally Friendly Synthesis of Highly Monodisperse Biocompatible Gold Nanoparticles with Urchin-like Shape. Langmuir 2008, 24, 1058-1063. [CrossRef] [PubMed]

33. Yuan, H.; Fales, A.M.; Vo-Dinh, T. TAT Peptide-Functionalized Gold Nanostars: Enhanced Intracellular Delivery and Efficient NIR Photothermal Therapy Using Ultralow Irradiance. J. Am. Chem. Soc. 2012, 134, 11358-11361. [CrossRef] [PubMed]

34. Nergiz, S.Z.; Gandra, N.; Tadepalli, S.; Singamaneni, S. Multifunctional Hybrid Nanopatches of Graphene Oxide and Gold Nanostars for Ultraefficient Photothermal Cancer Therapy. ACS Appl. Mater. Interfaces 2014, 6, 16395-16402. [CrossRef]

35. Kong, G.; Braun, R.D.; Dewhirst, M.W. Hyperthermia enables tumor-specific nanoparticle delivery: Effect of particle size. Cancer Res. 2000, 60, 4440-4445.

36. Eschwège, P.; de Ledinghen, V.; Camilli, T.; Kulkarni, S.; Dalbagni, G.; Droupy, S.; Jardin, A.; Benoît, G.; Weksler, B.B. Arachidonic acid and prostaglandins, inflammation and oncology. Presse Med. 2001, 30, 508-510.

37. Williams, C.S.; Mann, M.; Dubois, R.N. The role of cyclooxygenases in inflammation, cancer, and development. Oncogene 1999, 18, 7908-7916. [CrossRef]

38. Harris, R.E.; Namboodiri, K.K.; Farrar, W.B. Nonsteroidal Antiinflammatory Drugs and Breast Cancer. Epidemiology 1996, 7, 203-205. [CrossRef]

39. Sappayatosok, K.; Maneerat, Y.; Swasdison, S.; Viriyavejakul, P.; Dhanuthai, K.; Zwang, J.; Chaisri, U. Expression of pro-inflammatory protein, iNOS, VEGF and COX-2 in oral squamous cell carcinoma (OSCC), relationship with angiogenesis and their clinico-pathological correlation. Med. Oral Patol. Oral Cir. Bucal 2009, 14, E319-E324.

40. Raspollini, M.R.; Amunni, G.; Villanucci, A.; Boddi, V.; Taddei, G.L. Increased cyclooxygenase-2 (COX-2) and P-glycoprotein-170 (MDR1) expression is associated with chemotherapy resistance and poor prognosis. Int. J. Gynecol. Cancer 2005, 15, 255-260. [CrossRef]

41. Sheng, H.; Shao, J.; Morrow, J.D.; Beauchamp, R.D.; DuBois, R.N. Modulation of apoptosis and Bcl-2 expression by prostaglandin E2 in human colon cancer cells. Cancer Res. 1998, 58, 362-366. [PubMed]

42. Oshima, M.; Dinchuk, J.E.; Kargman, S.L.; Oshima, H.; Hancock, B.; Kwong, E.; Trzaskos, J.M.; Evans, J.F.; Taketo, M.M. Suppression of Intestinal Polyposis in Apc $\Delta 716$ Knockout Mice by Inhibition of Cyclooxygenase 2 (COX-2). Cell 1996, 87, 803-809. [CrossRef] 
43. Tsujii, M.; Kawano, S.; DuBois, R.N. Cyclooxygenase-2 expression in human colon cancer cells increases metastatic potential. Proc. Natl. Acad. Sci. USA 1997, 94, 3336-3340. [CrossRef] [PubMed]

44. Masferrer, J.L.; Koki, A.; Seibert, K. COX-2 Inhibitors: A New Class of Antiangiogenic Agents. Ann. N. Y. Acad. Sci. 1999, 889, 84-86. [CrossRef]

45. Tsujii, M.; Kawano, S.; Tsuji, S.; Sawaoka, H.; Hori, M.; DuBois, R.N. Cyclooxygenase regulates angiogenesis induced by colon cancer cells. Cell 1998, 93, 705-716. [CrossRef]

46. Huang, D.S.; Shen, K.Z.; Wei, J.F.; Liang, T.B.; Zheng, S.S.; Xie, H.Y. Specific COX-2 inhibitor NS398 induces apoptosis in human liver cancer cell line HepG2 through BCL-2. World J. Gastroenterol 2005, 11, $204-207$. [CrossRef]

47. McCarty, M.F.; Block, K.I. Preadministration of high-dose salicylates, suppressors of NF-kappaB activation, may increase the chemosensitivity of many cancers: An example of proapoptotic signal modulation therapy. Integr. Cancer Ther. 2006, 5, 252-268. [CrossRef]

48. Kang, H.K.; Lee, E.; Pyo, H.; Lim, S.J. Cyclooxygenase-independent down-regulation of multidrug resistance-associated protein-1 expression by celecoxib in human lung cancer cells. Mol. Cancer Ther. 2005, 4, 1358-1363. [CrossRef]

49. Liu, G.; Gao, N.; Zhou, Y.; Nie, J.; Cheng, W.; Luo, M.; Mei, L.; Zeng, X.; Deng, W. Polydopamine-Based "Four-in-One" Versatile Nanoplatforms for Targeted Dual Chemo and Photothermal Synergistic Cancer Therapy. Pharmaceutics 2019, 11, 507. [CrossRef]

50. Zheng, C.; Zheng, M.; Gong, P.; Deng, J.Z.; Yi, H.Q.; Zhang, P.F.; Zhang, Y.J.; Liu, P.; Ma, Y.F.; Cai, L.T. Polypeptide cationic micelles mediated co-delivery of docetaxel and siRNA for synergistic tumor therapy. Biomaterials 2013, 34, 3431-3438. [CrossRef]

51. Pitchaimani, A.; Nguyen, T.D.T.; Aryal, S. Natural killer cell membrane infused biomimetic liposomes for targeted tumor therapy. Biomaterials 2018, 160, 124-137. [CrossRef] [PubMed]

52. Tezgel, O.; Szarpak-Jankowska, A.; Arnould, A.; Auzély-Velty, R.; Texier, I. Chitosan-lipid nanoparticles (CS-LNPs): Application to siRNA delivery. J. Colloid Interface Sci. 2018, 510, 45-56. [CrossRef] [PubMed]

53. Han, J.; Wang, Q.; Zhang, Z.; Gong, T.; Sun, X. Cationic bovine serum albumin based self-assembled nanoparticles as siRNA delivery vector for treating lung metastatic cancer. Small 2014, 10, 524-535. [CrossRef] [PubMed]

54. Zhu, H.Y.; Zhang, S.Y.; Ling, Y.; Meng, G.L.; Yang, Y.; Zhang, W. pH-responsive hybrid quantum dots for targeting hypoxic tumor siRNA delivery. J. Control. Release 2015, 220, 529-544. [CrossRef]

55. Xiong, X.B.; Lavasanifar, A. Traceable Multifunctional Micellar Nanocarriers for Cancer-Targeted Co-delivery of MDR-1 siRNA and Doxorubicin. ACS Nano 2011, 5, 5202-5213. [CrossRef]

56. Ganta, S.; Devalapally, H.; Shahiwala, A.; Amiji, M. A review of stimuli-responsive nanocarriers for drug and gene delivery. J. Control Release 2008, 126, 187-204. [CrossRef]

57. López-Noriega, A.; Ruiz-Hernández, E.; Quinlan, E.; Storm, G.; Hennink, W.E.; O’Brien, F.J. Thermally triggered release of a pro-osteogenic peptide from a functionalized collagen-based scaffold using thermosensitive liposomes. J. Control Release 2014, 187, 158-166. [CrossRef]

58. Simons, A.L.; Ahmad, I.M.; Mattson, D.M.; Dornfeld, K.J.; Spitz, D.R. 2-Deoxy-D-glucose combined with cisplatin enhances cytotoxicity via metabolic oxidative stress in human head and neck cancer cells. Cancer Res. 2007, 67, 3364-3370. [CrossRef]

59. Simons, A.L.; Fath, M.A.; Mattson, D.M.; Smith, B.J.; Walsh, S.A.; Graham, M.M.; Hichwa, R.D.; Buatti, J.M.; Dornfeld, K.; Spitz, D.R. Enhanced response of human head and neck cancer xenograft tumors to cisplatin combined with 2-deoxy-D-glucose correlates with increased 18 F-FDG uptake as determined by PET imaging. Int. J. Radiat. Oncol. Biol. Phys. 2007, 69, 1222-1230. [CrossRef]

60. Maschek, G.; Savaraj, N.; Priebe, W.; Braunschweiger, P.; Hamilton, K.; Tidmarsh, G.F.; Young, L.R.D.; Lampidis, T.J. 2-Deoxy-D-glucose Increases the Efficacy of Adriamycin and Paclitaxel in Human Osteosarcoma and Non-Small Cell Lung Cancers in Vivo. Cancer Res. 2004, 64, 31-34. [CrossRef]

61. Ponce, A.M.; Vujaskovic, Z.; Yuan, F.; Needham, D.; Dewhirst, M.W. Hyperthermia mediated liposomal drug delivery. Int. J. Hyperth. 2006, 22, 205-213. [CrossRef] [PubMed]

62. Esquivel, J. Technology of hyperthermic intraperitoneal chemotherapy in the United States, Europe, China, Japan, and Korea. Cancer J. 2009, 15, 249-254. [CrossRef] [PubMed]

63. O'Neill, K.L.; Fairbairn, D.W.; Smith, M.J.; Poe, B.S. Critical parameters influencing hyperthermia-induced apoptosis in human lymphoid cell lines. Apoptosis 1998, 3, 369-375. [CrossRef] [PubMed] 
64. Fukami, T.; Nakasu, S.; Baba, K.; Nakajima, M.; Matsuda, M. Hyperthermia induces translocation of apoptosis-inducing factor (AIF) and apoptosis in human glioma cell lines. J. Neurooncol. 2004, 70, 319-331. [CrossRef] [PubMed]

65. Frank, S.; Oliver, L.; Lebreton-De Coster, C.; Moreau, C.; Lecabellec, M.T.; Michel, L.; Vallette, F.M.; Dubertret, L.; Coulomb, B. Infrared Radiation Affects the Mitochondrial Pathway of Apoptosis in Human Fibroblasts. J. Investig. Dermatol. 2004, 123, 823-831. [CrossRef] [PubMed]

66. Kapse-Mistry, S.; Govender, T.; Srivastava, R.; Yergeri, M. Nanodrug delivery in reversing multidrug resistance in cancer cells. Front. Pharmacol. 2014, 5, 159. [PubMed]

67. Meng, H.; Mai, W.X.; Zhang, H.; Xue, M.; Xia, T.; Lin, S.; Wang, X.; Zhao, Y.; Ji, Z.X.; Zink, J.I.; et al. Codelivery of an optimal drug/siRNA combination using mesoporous silica nanoparticles to overcome drug resistance in breast cancer in vitro and in vivo. ACS Nano 2013, 7, 994-1005. [CrossRef]

68. Nam, J.; Son, S.; Ochyl, L.J.; Kuai, R.; Schwendeman, A.; Moon, J.J. Chemo-photothermal therapy combination elicits anti-tumor immunity against advanced metastatic cancer. Nature Commun. 2018, 9, 1074. [CrossRef]

69. Xu, C.; Chen, F.; Valdovinos, H.F.; Jiang, D.; Goel, S.; Yu, B.; Sun, H.; Barnhart, T.E.; Moon, J.J.; Cai, W.B. Bacteria-like mesoporous silica-coated gold nanorods for positron emission tomography and photoacoustic imaging-guided chemo-photothermal combined therapy. Biomaterials 2018, 165, 56-65. [CrossRef]

70. You, Y.H.; Lin, Y.F.; Nirosha, B.; Chang, H.T.; Huang, Y.F. Polydopamine-coated gold nanostar for combined antitumor and antiangiogenic therapy in multidrug-resistant breast cancer. Nanotheranostics 2019, 3, $266-283$. [CrossRef]

71. Li, Z.; Chen, Y.; Yang, Y.; Yu, Y.; Zhang, Y.H.; Zhu, D.H.; Yu, X.P.; Ouyang, X.X.; Xie, Z.Y.; Zhao, Y.L. Recent Advances in Nanomaterials-Based Chemo-Photothermal Combination Therapy for Improving Cancer Treatment. Front. Bioeng. Biotechnol. 2019, 7, 293. [CrossRef] [PubMed]

72. Li, C.; Yang, X.Q.; Zhang, M.Z.; Song, Y.Y.; Cheng, K.; An, J.; Zhang, X.S.; Xuan, Y.; Liu, B.; Zhao, Y.D. In vivo Imaging-Guided Nanoplatform for Tumor Targeting Delivery and Combined Chemo-, Gene- and Photothermal Therapy. Theranostics 2018, 8, 5662-5675. [CrossRef] [PubMed]

(C) 2019 by the authors. Licensee MDPI, Basel, Switzerland. This article is an open access article distributed under the terms and conditions of the Creative Commons Attribution (CC BY) license (http://creativecommons.org/licenses/by/4.0/). 